The Six Ways to Well-Being (6W-WeB):

\title{
Assessing the Frequency of and Motivation for Six Behaviours Linked to Well-Being
}

Geetanjali Basarkod $^{1 *}$, Baljinder K. Sahdra ${ }^{1}$, Nic Hooper ${ }^{2}$, \& Joseph Ciarrochi ${ }^{1}$

${ }^{1}$ Institute for Positive Psychology and Education, Australian Catholic University, North Sydney, NSW, Australia

${ }^{2}$ Department of Health and Social Sciences, University of the West of England, Bristol, United Kingdom

\section{Author Notes}

*Corresponding author.

Institute for Positive Psychology and Education, Australian Catholic University, North Sydney, NSW 2060, Australia

geetanjali.basarkod@acu.edu.au

The authors declare that they have no conflicts of interest.

Funding: This study was partially funded by the Community Grant from the Australia and New Zealand Chapter of the Association of Contextual Behavioral Science 


\begin{abstract}
Contextual Behavioural Science (CBS) interventions focus on activating valueconsistent behaviours, yet the outcomes measured in these interventions often focus on internal states. Building on past CBS work, personal strivings research, and selfdetermination theory, we developed a new behaviour-focused measure of valued action, the Six Ways to Well-Being (6W-WeB). This measure captures both the specific actions individuals engage in as well as why they do so (i.e., underlying values). Participants in Study 1 (American sample; $\mathrm{N}_{1}=1800,60.3 \%$ female, Age: $M=40.9, S D=13.21$ ), Study 2 (Australian sample; $\mathrm{N}_{2}=855,47.3 \%$ female, Age: $M=38.16, S D=13.35$ ), and Study 3 (Australian adolescent sample; $\mathrm{N}_{3}=518,100 \%$ female, Age: $M=14.29, S D=1.46$ ) completed the $6 \mathrm{~W}-\mathrm{WeB}$ and theoretically-relevant criterion measures of flourishing, psychological distress, experiential avoidance, and nonattachment. Confirmatory factor analysis supported a bifactor model, with three global factors (behaviour engagement, activity importance, and activity pressure), and six behaviour-specific factors (connecting with others, challenging oneself, giving to others, engaging in physical activity, embracing the moment, and caring for oneself), that was invariant across gender, age, and country of sampling. The subscales of the $6 \mathrm{~W}-\mathrm{WeB}$ were linked to the theoretically-relevant variables in meaningful and expected ways. Additionally, in a test of known-groups validity, the 6WWeB successfully differentiated between participants who met criteria for high psychological distress and those who did not. The results suggest that the new measure can be a clinically relevant tool, helping CBS practitioners identify the specific behaviour domains that can promote their clients' value-consistent living.
\end{abstract}

Keywords: valued action; behaviour; motivation; well-being; questionnaire validation 
The benefits of experiencing relatively high levels of positive states, such as joy, and low levels of negative states, such as anxiety, have been well established (Fredrickson, 2001; Oswald, Proto, \& Sgroi, 2015). For instance, positive emotions enable individuals to be more creative, productive, and optimistic (for a review, see Lyubomirsky, King, \& Diener, 2005). Logically, interventions may seek to increase positive affect and decrease unhelpful negative states, but direct attempts to change internal states can, at times, be counterproductive (Ciarrochi, Atkins, Hayes, Sahdra, \& Parker, 2016). Distracting oneself from negative thoughts to improve one's mood, for instance, has been shown to reduce positive affect and increase disappointment at one's mood (Ford \& Mauss, 2014). In light of these findings, Contextual Behavioural Science (CBS) interventions, such as Acceptance and Commitment Therapy (ACT), shift the focus from how individuals feel to what they do in relation to those feelings (Ciarrochi et al., 2016). Even though CBS interventions do not directly target wellbeing or the reduction of distress symptoms, they are useful in improving well-being and treating many mental health conditions (Hooper \& Larsson, 2015). These improvements, in part, occur through increases in value-consistent behaviours (Gloster et al., 2017), which are personally meaningful behaviours that tend to be intrinsically driven and not extrinsically motivated. Since such behaviours are crucial to changes in well-being and mental health, their measurement and clinical monitoring are important goals for researchers and clinicians.

\section{Assessing Valued Action}

Valued action can be thought of as comprising two components: values (i.e., things that are personally meaningful, or 'why' individuals engage in actions) and action (i.e., 'what' an individual does to live in accordance with their values). Therefore, to gain a complete understanding of an individual's valued action, one can measure 'what' specific actions an individual engages in as well as 'why' they engage in those behaviours. Most current measures of valued action tend to assess the importance of broad life domains (e.g., 
family or work), and how successfully individuals live in value-consistent ways within these domains. They tend not to measure the specific actions that enable people to live in valueconsistent ways. For instance, the Valued Living Questionnaire (VLQ) assesses how much importance an individual places on ten life domains (family, intimate relationships, parenting, friends, work, education, recreation, spirituality, community life, and physical self-care) and the extent to which they have acted in line with their values in each domain that week (Wilson, Sandoz, Kitchens, \& Roberts, 2010). When used in clinical settings, such a questionnaire enables the assessment of 'why' a client may do things (e.g., because they highly value 'family'), but it does not provide information about 'what' specifically the client may do to act in accordance with their values (e.g., have dinner with their family without turning on the television). Therefore, while current valued action questionnaires have clinical utility (e.g., Dahl, Wilson, \& Nilsson, 2004), they are limited by virtue of not identifying specific actions that can be the target of behaviour-focused interventions.

This limitation may be addressed by the Personal Strivings Assessment Packet (PSAP; Emmons, 1986), a measure commonly used in the personal strivings literature. The PSAP contains an idiographic component that requires respondents to generate a list of 15 personal strivings, and a quantitative component wherein each striving is scored on several dimensions (e.g., happiness, value, commitment, and importance) as well as on five rating scales assessing the reasons (extrinsic, introjected, identified, and intrinsic motives) for each striving. Developing a questionnaire similar to the PSAP could not only allow individuals to specify exactly what behaviours they engage in (the 'what' of valued action), but it could also assess their reasons for engaging in each behaviour (the 'why' of valued action). However, the PSAP is limited in that it does not systematically encourage people to evaluate all domains of valued activity. When asked to freely list personal strivings, people may selectively focus on just some domains, such as work, academics, or health, and ignore 
others, such as physical health. Additionally, the PSAP focuses on future-oriented objectives that may not translate into present-moment behaviours.

A major goal of the present study is to validate a new questionnaire that measures both the 'what' and the 'why' of valued action and addresses the limitations of the PSAP. Specifically, the questionnaire utilises evidence-based question prompts (discussed in the next section) to encourage people to reflect on the full range of life domains, not just those that are salient, while also assessing present-moment behaviours that are linked to better wellbeing.

\section{The 'What' of Valued Action}

In 2008, the government of the United Kingdom, as part of the work carried out under the Foresight Project, commissioned the New Economic Foundation (NEF) to review the literature and identify the behaviours that promote well-being at the individual level. The NEF narrowed down the most important behaviours, or daily activities, to: connect (social relationships), keep learning (challenging yourself by learning new things), give (giving to others), be active (engage in physical activity), and take notice (being mindful) (Aked, 2011). This list was intentionally restricted to five actions for simplicity (to create an equivalent of the 'five serves of fruit and vegetables a day' for physical health). However, in addition to these five behaviours, there is also overwhelming support in the literature for the importance of self-care behaviours such as eating well and sleeping enough (Christensen, 2001;

Ciarrochi, Bailey, \& Harris, 2015; Haack \& Mullington, 2005). While a comprehensive review of the associations between these actions and well-being is beyond the scope of this paper (see Basarkod, 2019 for a review), we provide a brief overview below.

Connecting with others and having healthy social relationships predicts well-being across cultures and ages (e.g., Huxhold, Miche, \& Schüz, 2013; Lansford, Antonucci, Akiyama, \& Takahashi, 2005), while the absence of good quality relationships is associated 
with depression, anxiety, and loneliness (Cohen \& Syme, 1985; Rowe \& Kahn, 1998). Learning, or challenging oneself, is linked with improved health behaviours, self-efficacy, life satisfaction (Feinstein \& Hammond, 2004), quality of life (Jenkins, 2011), and fewer depressive symptoms (Kirkwood, Bond, May, McKeith, \& Teh, 2008). Giving to others, or engaging in helping behaviours, is associated with higher levels of happiness (Krueger, Hicks, \& McGue, 2001), better mental health (Schwartz, Meisenhelder, Ma, \& Reed, 2003), and a lower risk of premature mortality for individuals with high stress levels (Poulin, Brown, Dillard, \& Smith, 2013). Being active, or engaging in physical activity, is linked to reduced mental ill-health, and improved well-being (Biddle \& Asare, 2011), life satisfaction, and happiness (Morgan \& Bath, 1998). Engaging in exercise also prevents the onset and reduces pre-existing symptoms of depression and anxiety (Biddle \& Asare, 2011). Taking notice, or embracing the moment, is predictive of better stress reactivity (Davidson et al., 2003), positive mental states, and heightened self-knowledge (Brown \& Ryan, 2003). Caring for oneself, such as by sleeping and eating well, has been shown to improve physical and mental health (Christensen, 2001; Ciarrochi, Bailey, et al., 2015; Haack \& Mullington, 2005), while the lack of such activity is associated with lower levels of happiness and life satisfaction (Easterlin, 2003; Mehnert, Krauss, Nadler, \& Boyd, 1990).

\section{The 'Why' of Valued Action}

The six behaviours describe 'what' people do, but do not capture 'why' people engage in these actions. Self-determination theory (SDT) suggests that the ability of an action to promote well-being depends on the form of one's motivation (Deci \& Ryan, 1985). People thrive when they engage in behaviours they find personally meaningful and inherently enjoyable, that is, when their behaviours are autonomously motivated. For example, leisuretime physical activity, assumed to be autonomously motivated, is positively associated with subjective well-being (Jurakić, Pedišić, \& Greblo, 2010) and negatively linked with mental 
health disorders (Pickett, Yardley, \& Kendrick, 2012). Similarly, autonomously engaging in challenging activities increases enjoyment and sense of vitality (Deci \& Ryan, 1985). On the flipside, engaging in action because of controlled motivation, either to appease others or because of an internal pressure (e.g., guilt), may cause mental health to deteriorate (Deci \& Ryan, 2008). Thus, not only is the form of behaviour important for well-being, but the form of motivation also matters. Putting the motivational literature into the context of third wave therapies like ACT, we consider behaviours to be 'valued' to the extent that they are driven by autonomous and not controlled forms of motivation.

\section{Current Study}

The aim of the current study was to develop and validate a new questionnaire called the Six Ways to Well-Being $(6 \mathrm{~W}-\mathrm{WeB})$. The $6 \mathrm{~W}-\mathrm{WeB}$ assesses the frequency and motivation for six behaviour patterns - connecting with others, challenging oneself, giving to others, engaging in physical activity, embracing the moment, and caring for oneself. In this paper, we seek to assess the factor structure of the $6 \mathrm{~W}-\mathrm{WeB}$, its internal reliability, as well as its criterion validity in terms of correlations with theoretically relevant variables of flourishing, psychological distress, experiential avoidance, and nonattachment.

Past research suggests that there are individual differences in the extent to which people feel autonomy and pressure across all activity domains in their life (Ciarrochi \& Bailey, 2008; Ryan \& Deci, 2017). For example, some people feel high pressure and low valuing of activities across all domains. Despite these global tendencies, people can distinguish between different domains of activity, placing more importance on some behaviours compared to others (Wilson et al., 2010). For instance, people may be more autonomously motivated to connect with others than to challenge themselves. Based on this reasoning, we hypothesise that people will show both general tendencies across domains (individual differences in autonomous and controlled motivation), as well as specific 
preferences within domains (e.g., preferences for connecting type activities over challenging type activities). Specifically, a bifactor model that captures three global factors, namely behaviour engagement, activity importance, and activity pressure, as well as six specific domain factors of behaviour (i.e., connecting with others, challenging oneself, giving to others, engaging in physical activity, embracing the moment, and caring for oneself) will fit the data well (Hypothesis 1a). Additionally, the bifactor model will fit the data better than the models that assume only three global factors or only six specific factors (Hypothesis 1b).

Based on the evidence discussed in previous sections, we hypothesise that engaging in valued action (behaviour engagement) will be positively correlated with flourishing and negatively correlated with psychological distress (Hypothesis 2a). In addition, the more one engages in activities for autonomous reasons (activity importance) and not for controlled reasons (activity pressure), the greater one's level of flourishing and lower one's level of psychological distress will be (Hypothesis 2b). Higher scores on the six behaviour domains will also be associated with greater levels of flourishing and lower levels of psychological distress (Hypothesis 2c).

Given that the $6 \mathrm{~W}-\mathrm{WeB}$ is aimed for use with clinical populations, it is important to show that the $6 \mathrm{~W}-\mathrm{WeB}$ links substantially with clinical indices of distress. We hypothesise that participants who meet criteria for high psychological distress will show lower levels of behaviour engagement, activity importance, and higher levels of activity pressure, while participants who do not meet such criteria will show the opposite pattern (Hypothesis 3a). Individuals who meet criteria for psychological distress will also have lower mean scores on the six behaviour domains compared to those who do not meet criteria (Hypothesis $\mathbf{3 b}$ ).

Experiential avoidance and nonattachment are relevant for the construct validity of $6 \mathrm{~W}-\mathrm{WeB}$. Experiential avoidance measures the extent to which people seek to push away unpleasant experiences, in a way that interferes with valued action (Sahdra, Ciarrochi, Parker, 
\& Scrucca, 2016), and nonattachment measures the extent that people let go off positive states, in a way that supports valued action (Sahdra, Ciarrochi, \& Parker, 2016; Sahdra et al., 2016; Sahdra et al., 2017; Sahdra, Shaver, \& Brown, 2010). Therefore, we hypothesise that the global subscales of behaviour engagement and activity importance will be negatively correlated with experiential avoidance and positively correlated with nonattachment, while the global subscale of activity pressure will be positively correlated with experiential avoidance and negatively linked with nonattachment (Hypothesis 4a). All six domain subscales will be negatively correlated with experiential avoidance and positively correlated with nonattachment (Hypothesis 4b).

In Study 1 of this paper, we first test the factor structure of the $6 \mathrm{~W}-\mathrm{WeB}$ using data from a large, representative American sample (Hypothesis 1). We then examine how each of the $6 \mathrm{~W}-\mathrm{WeB}$ subscales are related to the criterion measures (Hypotheses 2 and 4). We also test how the patterns of $6 \mathrm{~W}-\mathrm{WeB}$ subscale scores would be different for individuals who meet criteria for high psychological distress and those who do not (Hypothesis 3 ). We seek to replicate these findings in Studies 2 (Australian community sample) and 3 (Australian adolescent sample). Lastly, we combine data from all three samples to test the measurement invariance of the $6 \mathrm{~W}-\mathrm{WeB}$ factor structure across age, gender, and country, as well as the factor loadings of the $6 \mathrm{~W}-\mathrm{WeB}$ items on the final model's latent factors.

\section{Study 1: Initial Validation}

\section{Participants and Design}

Data from 1,800 participants from the general population in America were purchased from a professional survey company. These participants ranged in age from of 18 to 65 years $(M=40.9, S D=13.21)$ and $60.3 \%$ of them were female. Further demographic information regarding the ethnicity, income, and education of these participants is presented in Table 1. Participants who gave their consent on the first page of the survey (as was the case for all 
subsequent studies), proceeded to answer a 30-minute-long questionnaire. For completion, the survey company offered participants a choice to either donate $\$ 0.50$ to a charity or enter a sweepstake to win $\$ 100$.

\section{Measures}

All participants completed the $6 \mathrm{~W}-\mathrm{WeB}$. To reduce participant burden, we utilised a planned missing data design (e.g., Ciarrochi, Sahdra, Marshall, Parker, \& Horwath, 2015), whereby the rest of the data were collected in two parts. In the first part, some participants answered mental health and CBS-related measures, while others answered questions on body image. In the second part, all participants answered questions on psychological distress, nonattachment, and body image. Therefore, out of the 1800 participants, 500 answered the flourishing and experiential avoidance questionnaires, and 1262 answered the psychological distress and nonattachment questionnaires. The data related to body image measures are not relevant to this study and are reported elsewhere (Basarkod, Sahdra, \& Ciarrochi, 2018). Missing data in the confirmatory factor analysis models were dealt with using full information maximum likelihood estimation, and pair-wise deletion in all other analyses.

Ways to well-being. The Six Ways to Well-Being (6W-WeB), presented in Supplementary Materials 1A, was designed to measure the frequency of and (autonomous vs. controlled) motivation for engaging in six behavioural patterns that promote well-being. Participants were asked to report two typical ways in which they engaged in each of the following domains: connecting with others, challenging oneself, giving to others, engaging in physical activity, embracing the moment, and caring for oneself. For each example, participants rated the extent to which they were satisfied with the frequency of engagement in that activity, the extent to which they engaged in that behaviour because it was personally important or meaningful to them, and the extent to which they felt pressured to engage in that behaviour. All items were rated on a Likert type scale from 1 (Strongly Disagree) to 6 
(Strongly Agree). The questionnaire had 12 qualitative and 36 quantitative items, along with an optional section where participants could report an example of an activity they felt did not fall within the six categories and rate this example on the three aforementioned scales. As this category was optional, our quantitative analyses did not include these items (we do, however, report on the idiographic responses in this category, and present these results in Study 3).

Flourishing. We used a 12-item measure to assess flourishing (Keyes, 2006) with 3 items measuring emotional flourishing (e.g. "In the past month, how often have you felt happy?"; $\alpha=.86$ ), 4 items measuring psychological flourishing (e.g. "In the past month, how often did you feel good at managing the responsibilities of your daily life?"; $\alpha=.82$ ), and 5 items measuring social flourishing (e.g. "In the past month, how often did you feel that you had something important to contribute to society?"; $\alpha=.87)$. All items were rated on a Likert type scale from 0 (Never) to 5 (Every Day).

Psychological distress. We used the General Health Questionnaire-12 (GHQ-12; Goldberg, 1992) to measure psychological distress. Each of the 12 items were rated on a 4point scale, with labels varying across items (e.g. not at all to much more than usual). Example items include: "Have you recently lost much sleep over worry" and "have you recently been thinking of yourself as a worthless person". The Likert method of scoring was used (scored from 0 to 3), and higher scores were indicative of greater psychological distress $(\alpha=.91)$. GHQ-12 has been used in prior research to identify individuals with mental health disorders as classified by the Diagnostic and Statistical Manual of Mental Disorders, fifth edition (DSM-V; e.g. Cornelius, Groothoff, van der Klink, \& Brouwer, 2013). We used the cut-off point of 11/12 to identify individuals with high psychological distress. This cut-off has been used with both clinical (e.g. Martin \& Newell, 2005) and non-clinical samples (e.g. Lundin, Hallgren, Theobald, Hellgren, \& Torgén, 2016), and shows high specificity and sensitivity in identifying individuals with psychological distress (Donath, 2001). 
Experiential avoidance. A 30-item short form of the Multidimensional Experiential Avoidance Questionnaire was used to measure experiential avoidance (Sahdra, Ciarrochi, Parker, \& Scrucca, 2015). The measure consists of 5 items measuring each of the six subscales of avoidance: behavioural avoidance (e.g. "I avoid situations if there is a chance that I'll feel nervous"; $\alpha=.82$ ), distress aversion (e.g. "I'd do anything to feel less stressed"; $\alpha=.82$ ), distraction and suppression (e.g. "When a negative thought comes up, I immediately try to think of something else"; $\alpha=.84$ ), repression/denial (e.g. "I feel disconnected from my emotions"; $\alpha=.82$ ), procrastination (e.g. "I won't do something until I absolutely have to"; $\alpha$ $=.79$ ), and distress endurance (e.g. "When working on something important, I won't quit even if thing get difficult"; $\alpha=.84$ ). Items were rated on a Likert type scale from 1 (Disagree Strongly) to 6 (Agree Strongly).

Nonattachment. To measure nonattachment, we used the Nonattachment Scale -7 (NAS-7; Elphinstone, Sahdra, \& Ciarrochi, 2015; Sahdra, Ciarrochi, Parker, Marshall, \& Heaven, 2015), a short form of the 30-item Nonattachment Scale (Sahdra et al., 2010). Each item was rated on a Likert type scale from 1 (Strongly Disagree) to 6 (Strongly Agree). Example items include: "I can enjoy pleasant experiences without needing them to last forever," and "I can let go of regrets and feelings of dissatisfaction about the past." Higher scores were indicative of greater nonattachment $(\alpha=.87)$.

\section{Results}

\section{Factor Structure and Reliability}

All analyses were conducted in an open source statistical programme, R (R Core Team, 2015). To test the factor structure of the $6 \mathrm{~W}-\mathrm{WeB}$, we conducted three confirmatory factor analyses (CFA) models using robust maximum likelihood estimation methods, as such estimates improve the accuracy of the results obtained from CFAs (Li, 2016). In keeping with commonly accepted criteria for adequate model fit, the Tucker-Lewis Index (TLI) and the 
comparative fit index $(\mathrm{CFI})$ should be $\geq .90$, and the root mean square error of approximation (RMSEA) should be $\leq .06$ (Hu \& Bentler, 1999; Kenny, Kaniskan, \& McCoach, 2014).

The first model comprised of three global factors of satisfaction with frequency (or behaviour engagement), autonomous motivation (or activity importance), and controlled motivation (or activity pressure) for engaging in behaviours. All satisfaction with frequency items across the six behaviours were loaded onto the first factor, all items measuring autonomy were loaded onto the second factor, and all items assessing controlled motivation were loaded onto the third factor. Additionally, all three global factors were allowed to correlate with each other. The fit indices of this model were not satisfactory: $\chi^{2}(591)=$ 6436.41, $p<.001, \mathrm{CFI}=.76, \mathrm{TLI}=.74, \mathrm{RMSEA}=.074,90 \%$ CI [.073 .075].

The second model comprised six domain factors - one for each of the six behaviours of connecting with others, challenging oneself, giving to others, engaging in physical activity, embracing the moment, and caring for oneself. For each domain factor, all the items for satisfaction with frequency, autonomous motivation, and controlled motivation assessing that behaviour, loaded onto that factor. All six domain factors were allowed to correlate with each other. The fit indices of this model were, again, unsatisfactory: $\chi^{2}(579)=13343.74, p<.001$, $\mathrm{CFI}=.47, \mathrm{TLI}=.43, \mathrm{RMSEA}=.111,90 \%$ CI $[.109 .112]$.

Lastly, we tested a bifactor CFA model which consisted of the three global factors as well as the six domain factors. In a bifactor model, each item loads onto two factors. Thus, for the $6 \mathrm{~W}-\mathrm{Web}$, each of the 36 quantitative items were loaded onto one global factor and one domain-specific factor. For instance, the item assessing satisfaction with frequency of engagement for connecting with others was loaded onto both the behaviour engagement factor and the connecting with others factor. The global factors were allowed to correlate with each other, the domain factors were allowed to correlate with each other, but, following best practice (Chen, West, \& Sousa, 2006), the residual correlations between global and 
domain factors were constrained to zero, i.e., the global and domain factors were orthogonal. This model showed close to adequate fit, substantially improving on the previous models: $\chi^{2}$ $(540)=2741.77, p<.001, \mathrm{CFI}=.91, \mathrm{TLI}=.89, \mathrm{RMSEA}=.048,90 \%$ CI $[.046 .049]$.

To examine whether there were any important sources of misfit in the bifactor model, we examined the modification indices. The top twenty modification indices are presented in Supplementary Material 2, Table S1. These indices indicated that the majority of misfit occurred within the specific behavioural factors (e.g., two pressure items within challenging oneself) and, therefore, did not challenge Hypothesis 1. Specifically, the misspecification lay in the residual correlations between the first and second example pressure items for the different behaviours, suggesting that pressure may be pervasive across items within the same domain. For instance, pressure felt for one instance of challenging oneself also tended to be felt for the second instance of challenging oneself. We added the residual correlations for the pressure items within each domain factor, and the model fit improved: $\chi^{2}(534)=2344.01, p<$ $.001, \mathrm{CFI}=.93, \mathrm{TLI}=.91, \mathrm{RMSEA}=.043,90 \% \mathrm{CI}[.042 .045]$. We, therefore, used this bifactor model for all further analyses. This bifactor CFA model is represented in Figure 1.

The alpha reliability estimates for the 9 subscales of the $6 \mathrm{~W}-\mathrm{WeB}$ are presented in Table 2 (subscales comprised all items that loaded onto each factor, with the pressure items reverse scored for domain subscales). All subscales showed adequate internal consistency. To increase statistical accuracy, the factor loadings of the bifactor model were examined using all available data (i.e., combined samples from all three studies), and are presented in Study 3.

\section{Correlations With Criterion Measures}

To inspect how the subscales of the $6 \mathrm{~W}-\mathrm{WeB}$ correlated with the criterion measures of flourishing, psychological distress, experiential avoidance, and nonattachment, we conducted zero-order correlations using the scale scores of the $6 \mathrm{~W}-\mathrm{WeB}$ measure (calculated 
as the average of all items that loaded onto each factor, with pressure items reverse scored for the domain subscales; more information in Supplementary Materials 1B) and the criterion variables. These correlations are presented in Table 2.

With respect to flourishing and psychological distress, behaviour engagement, activity importance, and the six behaviours were positively correlated with all three flourishing subscales and negatively correlated with psychological distress, while activity pressure had negative correlations with emotional and psychological flourishing and a positive correlation with psychological distress. These results may indicate that individuals who are more satisfied with their level of behaviour engagement, engage in activity because of autonomous rather than controlled motivation, and engage more in each of the six behaviour domains, experience greater well-being and lower psychological distress.

With regard to the experiential avoidance subscales, behaviour engagement had positive correlations with distraction and suppression and distress endurance, and a negative correlation with procrastination. Activity importance had the same pattern of correlations with the addition of a negative correlation with repression/denial. Activity pressure had positive correlations with behavioural avoidance, distress aversion, repression/denial, and procrastination, and a negative correlation with distress endurance. All six behaviours were positively correlated with behavioural avoidance, distress aversion, and distress endurance, and negatively correlated with repression/denial and procrastination. Connecting with others, challenging oneself, giving to others, and embracing the moment also had positive correlations with distraction/suppression. In general, these correlations indicate that individuals who do not avoid engaging in behaviours that may cause them to experience distressing emotions, seem to engage more in activities that are meaningful to them.

In terms of nonattachment, behaviour engagement, activity importance, and all six behaviours were positively correlated, while activity pressure was negatively correlated with 
nonattachment. These results suggest that individuals who are able to let go off and not cling on to positive experiences, appear to be more behaviourally active and do so because of autonomous reasons.

\section{Known-Groups Validity}

To test whether individuals who meet criteria for psychological distress and those who do not would respond differently to the $6 \mathrm{~W}-\mathrm{WeB}$, we divided the sample into two subgroups based on their scores on the GHQ-12. Individual with scores of 12 and over met the criteria for high psychological distress, while those with scores of 11 and under did not (Donath, 2001). We compared these two subgroups on their standardised scale scores of behaviour engagement, activity importance, and activity pressure, as well as the six behaviour domains. The results from these comparisons are represented visually in Figure 2 through bar plots with 95\% confidence intervals. Individuals experiencing high psychological distress tended to have lower scores on behaviour engagement and activity importance, and higher scores on activity pressure, compared to individuals who did not meet criteria. They also had lower scores on the six behaviours. These comparisons reveal that individuals who had lower levels of satisfaction with their behaviour engagement, engaged in activity because of controlled rather than autonomous reasons, and had lower levels of engagement in the six behaviours, were also likely to experience higher levels of psychological distress, compared to individuals who showed the opposite pattern of scores on the $6 \mathrm{~W}-\mathrm{WeB}$ subscales.

\section{Study 2: Replication in a Large Australian Sample}

\section{Participants and Design}

Data from 855 respondents from a representative sample of Australian adults were purchased from a professional survey company. These participants had the same age range as the previous sample, i.e. $18-65(M=38.16, S D=13.35)$ and $47.3 \%$ of them were female. Information regarding their ethnicity, income, and education is presented in Table 1. The 
survey company determined the incentives based on various factors (such as length of survey and target acquisition difficulty) and incentives could include cash, gift cards, or sweepstakes entrance. The survey took approximately 20 minutes to complete.

\section{Measures}

All participants in this study answered the $6 \mathrm{~W}-\mathrm{WeB}$ as well as the measures of flourishing (emotional flourishing $\alpha=.91$; psychological flourishing $\alpha=.84$; social flourishing $\alpha=.89)$ and psychological distress $(\alpha=.92)$.

\section{Results}

\section{Factor Structure and Reliability}

We tested the bifactor model of the $6 \mathrm{~W}-\mathrm{WeB}$ to inspect whether this model showed good fit to the data in an independent, Australian sample. The bifactor model (which included the correlated residuals from Study 1) fit the data adequately in this independent sample: $\chi^{2}$ $(534)=1399.92, p<.001, \mathrm{CFI}=.93, \mathrm{TLI}=.91, \mathrm{RMSEA}=.044,90 \%$ CI $[.041 .046]$. The alpha reliability estimates for the 9 subscales are presented in Table 3.

\section{Correlations With Theoretically-Relevant Measures}

We conducted zero-order correlations using the scale scores of the $6 \mathrm{~W}-\mathrm{WeB}$ measure and scale scores of the criterion measures. These results are presented in Table 3. Showing similar patterns of correlations as in Study 1, behaviour engagement, activity importance, and the six behaviour subscales had positive correlations with all three flourishing subscales and negative correlations with psychological distress. Activity pressure was negatively correlated with emotional and psychological flourishing, and positively correlated with psychological distress. As in Study 1, these results indicate that participants who reported greater satisfaction with their level of behaviour engagement, engaged in activity because of autonomous rather than controlled motivation, and had greater engagement in the six behaviour domains, tended to experience greater well-being and lower psychological distress. 


\section{Known-Groups Validity}

We compared individuals who met criteria for high psychological distress with those who did not, using the cut off scores of $11 / 12$ on the GHQ-12. Figure 2 visually represent these results through bar plots with $95 \%$ confidence intervals. The standardised $6 \mathrm{~W}-\mathrm{WeB}$ scale scores of participants in the two groups differed in the same pattern as was observed in Study 1 , on all three global scales and all six domain scales. These results imply that the $6 \mathrm{~W}-$ WeB may be able to differentiate between individuals experiencing psychological distress and those who do not.

\section{Study 3: Replication in an Adolescent Australian Sample}

\section{Participants and Design}

Data were gathered from a convenience sample that consisted of 518 respondents from an all-girls private high school in Sydney, Australia. Participants were from grades 711 , with an age range of $12-17(M=14.29, S D=1.46)$. The survey took approximately 30 minutes to complete. Questions about ethnicity, income, and education were not asked in this sample.

\section{Measures}

All participants completed the $6 \mathrm{~W}-\mathrm{WeB}$ questionnaire as well as the flourishing (emotional flourishing $\alpha=.87$; psychological flourishing $\alpha=.79$; social flourishing $\alpha=.84$ ) and nonattachment $(\alpha=.83)$ questionnaires.

\section{Results}

\section{Factor Structure and Reliability}

The final bifactor model of $6 \mathrm{~W}-\mathrm{WeB}$ showed adequate fit to the data in this third, independent sample: $\chi^{2}(534)=1034.44, \mathrm{p}<.001, \mathrm{CFI}=.91, \mathrm{TLI}=.90, \mathrm{RMSEA}=.043$, $90 \%$ CI [.039 .046]. The alpha reliability estimates for the subscales of the $6 \mathrm{~W}-\mathrm{WeB}$ are reported in Table 4. All subscales again showed adequate internal consistency. 


\section{Correlations With Theoretically-Relevant Measures}

We conducted zero-order correlations using the scale scores of the $6 \mathrm{~W}-\mathrm{WeB}$ measure and flourishing and nonattachment scales. These results are presented in Table 4. In this adolescent sample, behaviour engagement, activity importance, and the six behaviour subscales again had positive correlations with flourishing, while activity pressure had negative correlations with all three flourishing subscales. These results indicate that participants who were more satisfied with their level of engagement in the behaviours, were motivated for autonomous reasons rather than controlled reasons, and engaged more in the six behaviours, tended to report higher levels of flourishing.

Nonattachment had positive correlations with behaviour engagement, activity importance, and the six behaviours, and a negative correlation with activity pressure. As in Study 1 , these results further suggest that nonattached individuals may be more engaged in behaviours and do so because these behaviours are personally important to them.

\section{Analyses Using the Combined Sample}

In order to accurately examine the factor loadings and measurement invariance of the $6 \mathrm{~W}-\mathrm{WeB}$, we combined data from Studies 1, 2, and 3A. This was done as increasing the sample size increases the statistical accuracy of the covariance and variance estimates, which in turn reduces the error of estimation (Jackson, Gillaspy Jr, \& Purc-Stephenson, 2009). In addition, we report the most frequent responses to the open-ended questions for each study.

Factor loadings. The factor loadings of the $6 \mathrm{~W}-\mathrm{WeB}$ bifactor model using the combined samples are presented in Supplementary Material 3, Table S2. As expected in a bifactor model, the factor loadings of the items on the domain factors were smaller than the factor loadings of the items on the global factors. This is because the latent global factors partial out the variance that is common among all the items that load onto it, before the factor 
loadings of items on the latent domain factors are examined. Overall, the factor loadings of the $6 \mathrm{~W}-\mathrm{WeB}$ bifactor model were satisfactory.

Measurement invariance. We tested the measurement invariance of the $6 \mathrm{~W}-\mathrm{WeB}$ bifactor model across gender, age groups, and countries (i.e., America and Australia). Measurement invariance assesses whether the questionnaire measures the same construct across all groups. Multiple group CFAs were used where gender was split into male $(\mathrm{N}=$ 1163 ) and female $(\mathrm{N}=2007)$ (3 participant had missing gender data), age was split into two groups: 12 to $38.5(\mathrm{~N}=1851)$ and 38.5 to $65(\mathrm{~N}=1322)$, and country was split into America $(\mathrm{N}=1800)$ and Australia $(\mathrm{N}=1373)$. Five levels of invariance were tested: configural invariance models test the same underlying measurement structure, but all parameters are free to vary across groups; loading invariance models hold factor loadings constant across groups; intercept invariance models hold both factor loadings and intercepts constant across groups; residual invariance models hold factor loadings, intercepts, and residuals equal across groups; and means invariance models hold factor loadings, intercepts, residuals and means equal across groups. Table 5 shows the fit indices for these invariance models across gender and age. Results indicate that the $6 \mathrm{~W}-\mathrm{WeB}$ bifactor model was invariant across gender, age, as well as countries, as the fit indices of the model were acceptable even at the means invariance level.

Word frequency tabulation. To examine the typical ways in which participants engaged in each of the six behavioural domains in each study, the frequencies with which words appeared in participants' qualitative responses were calculated. The methodology used to calculate these word frequencies, along with the top 20 most frequently reported words in each of the six domains as well as in the 'other' category, are presented in Supplementary Material 4 (Tables S3-S5). As an example, the top three examples reported in Study 1 for connecting with others were "friend", "talk", and "phone"; "learn", "cook", and "work" for 
challenging oneself; "donate", "volunteer", and "help" for giving to others; "walk", "play", and "gym" for engaging in physical activity; "enjoy", "watch", and "attention" for embracing the moment; and "eat", "sleep", and "healthy" for caring for oneself. Results indicate that the majority of frequently reported words did not overlap between domains, i.e., the actions that individuals engaged in each of the domains seemed to be distinct. Additionally, the majority of words reported in the 'other' category were already captured by the six behaviour domains, such as "care", "read", and "family," suggesting that the 6W-WeB largely captured valued action.

\section{Discussion}

Using three independent samples, we aimed to (i) validate the factor structure of the Six Ways to Well-Being (6W-WeB), (ii) examine its construct validity in terms of correlations with theoretically-relevant variables of flourishing, psychological distress, experiential avoidance, and nonattachment, and (iii) compare individuals who had high psychological distress with those who did not. Results from Study 1 showed that the bifactor model was superior to alternate models with only three global factors or only six domain factors. The fit of the bifactor model was shown to be adequate in all three studies, confirming Hypothesis 1. This model was invariant across age and gender groups, as well as across countries, and the alpha reliability estimates and factor loadings were satisfactory. The correlations of the $6 \mathrm{~W}-\mathrm{WeB}$ with theoretically-relevant variables were in line with Hypotheses 2 and 4. Lastly, comparisons between participants who met criteria for high psychological distress indicated that the $6 \mathrm{~W}-\mathrm{WeB}$ could indeed differentiate between individuals from these two subgroups, confirming Hypothesis 3.

With regard to our first major aim, the results presented in this paper indicate that the bifactor structure of the $6 \mathrm{~W}-\mathrm{WeB}$ fit the data well in three independent samples with varied demographic features. Further, measurement invariance tests suggest that the $6 \mathrm{~W}-\mathrm{WeB}$ can 
be reliably used among males and females as well as young and old participants in both America and Australia. Interestingly, the modification indices indicated that some of the misspecification of the bifactor model lay in the correlated residuals between the first and second activity pressure items within each behaviour domain. These residual correlations could imply that felt pressure is pervasive across different activities within the same domain; if an individual feels pressured to challenge themselves in one way, they may also feel pressured to challenge themselves in other ways. These findings are consistent with past research. One study showed that students who had higher levels of controlled motivation in one subject at school also had higher controlled motivation in other subjects (Ratelle, Guay, Vallerand, Larose, and Senécal (2007). Further, the correlation between controlled motivation in different subject areas was higher than the correlations for either identified or autonomous motivation across subjects.

In our study, the pervasiveness of controlled motivation is also evident in the factor loadings of items on the latent constructs; items on the global factor of activity pressure had the largest factor loadings. These factor loadings suggest that most of the variance in items assessing pressure may be attributed to the global factor of activity pressure and that there is little variance left over in these items to be accounted for by the specific behaviour domains.

The word frequency tabulation of the idiographic responses was also in line with the factor structure of the $6 \mathrm{~W}-\mathrm{WeB}$. Specifically, the little overlap between examples reported in each of the six domains suggests that the six domains are most likely distinct. Additionally, the results suggest that a wide range of human valued action is captured by the six domains; the responses in the 'other' category were not novel.

With regard to the correlations of the $6 \mathrm{~W}-\mathrm{WeB}$ subscales with theoretically-relevant variables, behaviour engagement was associated with better mental health and well-being. According to a popular model of well-being, $50 \%$ of the variance in well-being is thought to 
be accounted for by biological indicators, $10 \%$ by demographics, and the remaining $40 \%$ by engaging in intentional activity (Lyubomirsky, Sheldon, and Schkade, 2005). The behavioural activation (BA) literature provides evidence for the positive association between intentional activity and well-being (see Mazzucchelli, Kane, \& Rees, 2010 for a metaanalysis). The aim of BA is to bring individuals into contact with positive reinforcements associated with behaviours by increasing their level of engagement in activity, which in turn, improves their well-being. The results of our study are in line with previous findings in so far as being satisfied with one's engagement in activity (i.e. thinking that one is engaging in activities enough) is related to higher well-being and lower psychological distress.

Activity importance was positively associated with mental health and well-being, while activity pressure showed the opposite pattern. Previous studies have reported similar results wherein individuals who act autonomously have higher levels of well-being and lower levels of mental illness, while those who engage in action because of controlled motivation experience greater levels of mental illness (Ryan \& Deci, 2017; Sheldon \& Kasser, 1995). The link between autonomous motivation and better mental health is further supported by our comparisons between individuals who met criteria for psychological distress and those who did not; the former had lower mean scores on behaviour engagement and activity importance than the latter while the opposite pattern was observed for the mean scores on activity pressure. In addition, psychologically distressed individuals also had lower mean scores for all six behaviour domains in both Studies 1 and 2.

In the three studies presented in this paper, all six behaviour subscales were consistently related to positive mental health outcomes. In terms of clinical utility, these results suggest that one may seek to increase autonomous engagement in any of the domains that the client chooses. Interestingly, connecting with others and engaging with physical activity had the strongest correlations with flourishing and psychological distress. These 
results are consistent with past evidence that underline the importance of social relationships and exercise for improved mental health and well-being (Azar, Ball, Salmon, \& Cleland, 2008; Biddle \& Ekkekakis, 2005; Endo, Heine, \& Lehman, 2000). For instance, a prospective study showed that a primary social network of less than three people predicts mental illness in the future, even after controlling for the presence of previous mental health disorders (Brugha et al., 2005), while a daily diary study showed that individuals have higher levels of life satisfaction on days they exercise compared to days they do not (Maher et al., 2013).

In terms of experiential avoidance, the distress endurance subscale had the strongest correlations with $6 \mathrm{~W}-\mathrm{WeB}$; it was positively correlated with behaviour engagement, activity importance, and the six behaviours, and negatively correlated with activity pressure. These correlations are of particular interest and relevance to CBS clinicians as distress endurance can be understood as a proxy for psychological flexibility. Psychological flexibility implies that an individual can act in value-consistent ways even in the face of internal difficulties (Hayes, Strosahl, \& Wilson, 2011). Having distressing thoughts and emotions in the face of difficulty may not be a barrier for meaningful activity for such individuals, allowing them to lead a more value-consistent life, in turn benefitting their well-being.

While psychological flexibility usually involves enduring what is difficult in order to do something that is meaningful, nonattachment involves a flexible way of relating to one's experiences without clinging on to positive (or avoiding negative) aspects of life (Sahdra et al., 2015). In Studies 1 and 3, nonattachment was positively correlated with behaviour engagement, activity importance, and the six behaviours, and negatively correlated with activity pressure. Our results suggest that individuals who are aware of the fleeting nature of experiences and do not cling to positive emotions, events, and ideals, are presumably more engaged in activities and do so because these actions are consistent with their values. Nonattached individuals may be more able to move towards meaningful action in their 
everyday life, without being held back by expectations of what their experiences should ideally be. The pattern of results we observed is consistent with past research showing that nonattachment is linked with lower levels of depression and anxiety (Sahdra et al., 2010), better mental health (Ciarrochi, Sahdra, Yap, \& Dicke, 2018), and high pro-sociality (Sahdra, Ciarrochi, Parker, Marshall, et al., 2015).

Overall, the results of the three studies presented in this paper suggest that the $6 \mathrm{~W}$ WeB may have treatment utility for clinicians (Ciarrochi, Zettle, et al., 2015). By using the $6 \mathrm{~W}-\mathrm{WeB}$, clinicians can identify the specific ways in which their client engages in six behaviour domains that capture a wide range of valued action. Further, the clinician will have insight into why their client engages in each action, enabling the clinician to capitalise on behaviours that are motivated by autonomous reasons. They could also explore if, and why, their client experiences controlled motivation to engage in action. The $6 \mathrm{~W}-\mathrm{WeB}$ could, therefore, not only identify behaviours that may form the target of intervention, but it could also provide information about the function of the behaviours the client engages in. The measure can, therefore, help a clinician to orient their clients towards valued actions, the central point of ACT interventions (Hayes, Strosahl, \& Wilson, 2011).

Even people who do not suffer from a clinical disorder could reflect on the typical behaviours they engage in in their everyday lives, by completing the $6 \mathrm{~W}-\mathrm{WeB}$. The $6 \mathrm{~W}-\mathrm{WeB}$ may provide a starting point of self-reflection; an examination of what the individual does, what they could do more of, and why they do what they do. Such self-reflection may enable individuals to change their behaviours, if needed, by engaging in the six domains of behaviour for autonomous reasons.

Although our studies show that the nine subscales of the $6 \mathrm{~W}-\mathrm{WeB}$ are linked with indices of well-being in expected ways, longitudinal research is needed to accurately call these behaviours 'ways' to well-being. Longitudinal studies can help assess the extent to 
which autonomously engaging in the six behaviours over time improve well-being and mental health, and provide evidence for causal ordering. We would expect the $6 \mathrm{~W}-\mathrm{WeB}$ to predict well-being, as previous longitudinal research has consistently shown valued action and autonomously motivated behaviour to be important for well-being (Gloster et al., 2017; Ryan \& Deci, 2017). Longitudinal research could also highlight the beneficial nature of some behaviours over others, enabling clinicians to reliably start behavioural activation in one domain (perhaps connecting with others) that could then be broadened out to the other five.

Our results are limited in generalisability due to the characteristics of our sample. While we attempted to test the pattern of scores for individuals with likely mental health problems based on previously established cut-offs, our sample was from the general population. The $6 \mathrm{~W}-\mathrm{WeB}$ should also be tested in non-western samples, although we would expect it to perform similarly in such samples. Past research has provided cross-cultural support for the links between (autonomous and controlled) motivation and well-being (Ryan \& Deci, 2017), as well as between valued activity and well-being (Hooper \& Larson, 2015).

Despite these limitations, our studies lend support to the factor structure, content validity, criterion validity, and usability of the $6 \mathrm{~W}-\mathrm{WeB}$. Our results add to the existing literature on valued action by (i) providing evidence for six specific behaviours domains that are linked to well-being, (ii) indicating that the more individuals are satisfied with their frequency of engagement in these six behaviours the more likely they are to experience wellbeing, and (iii) suggesting that if individuals engage in action because of autonomous rather than controlled motivation, they experience greater levels of well-being. Importantly, our results suggest that the $6 \mathrm{~W}-\mathrm{WeB}$ may facilitate clinical interventions by focusing clinicians on the specific behaviours that need to be targeted, allowing them to work with clients in meaningful ways. 


\section{References}

Aked, J. (2011). Five ways to wellbeing: new applications, new ways of thinking. London: New Economics Foundation.

Azar, D., Ball, K., Salmon, J., \& Cleland, V. (2008). The association between physical activity and depressive symptoms in young women: A review. Mental Health and Physical Activity, 1, 82-88. doi:10.1016/j.mhpa.2008.09.004

Basarkod, G. (2019). The Six Ways to Well-Being (6W-WeB): A new measure of valued action that targets the frequency and motivation for six behavioural patterns that promote well-being (Unpublished doctoral dissertation). Australian Catholic University, Sydney, Australia.

Basarkod, G., Sahdra, B. K., \& Ciarrochi, J. (2018). Body Image-Acceptance and Action Questionnaire-5: An Abbreviation Using Genetic Algorithms. Behavior Therapy, 49, 388-402. doi:10.1016/j.beth.2017.09.006.

Biddle, S. J., \& Asare, M. (2011). Physical activity and mental health in children and adolescents: A review of reviews. British Journal of Sports Medicine, 45, 886-895. doi:10.1136/bjsports-2011-090185

Biddle, S. J., \& Ekkekakis, P. (2005). Physically active lifestyles and well-being. In F. Huppert, N. Balyis, \& B. Keverne (Eds.), The science of well-being (pp. 140-168). Oxford: Oxford University Press.

Brown, K. W., \& Ryan, R. M. (2003). The benefits of being present: Mindfulness and its role in psychological well-being. Journal of Personality and Social Psychology, 84, 822848. doi:10.1037/0022-3514.84.4.822

Brugha, T. S., Weich, S., Singleton, N., Lewis, G., Bebbington, P. E., Jenkins, R., \& Meltzer, H. (2005). Primary group size, social support, gender and future mental health status 
in a prospective study of people living in private households throughout Great Britain. Psychological Medicine, 35, 705-714. doi:1017/S0033291704003903

Chen, F. F., West, S. G., \& Sousa, K. H. (2006). A Comparison of Bifactor and Second-Order Models of Quality of Life. Multivariate Behavioral Research, 41, 189-225. doi:10.1207/s15327906mbr4102_5

Christensen, L. (2001). The effect of food intake on mood. Clinical Nutrition, 20, 161-166. doi:10.1054/clnu.2001.0420

Ciarrochi, J., Atkins, P., Hayes, L., Sahdra, B. K., \& Parker, P. (2016). Contextual positive psychology: Policy recommendations for implementing positive psychology into schools. Frontiers in Psychology, 7, 1561. doi:10.3389/fpsyg.2016.01561.

Ciarrochi, J., \& Bailey, A. (2008). A CBT-practitioner's guide to ACT: How to bridge the gap between cognitive behavioral therapy and acceptance and commitment therapy. Oakland, CA: New Harbinger Publications.

Ciarrochi, J., Bailey, A., \& Harris, R. (2015). The weight escape. Penguin Group (Australia).

Ciarrochi, J., Sahdra, B, Yap, K., Dicke, T. (2018). Non-attached and well: A three-year longitudinal study into the role of nonattachment in the development of adolescent mental health. Manuscript under review

Ciarrochi, J., Zettle, R. D., Brockman, R., Duguid, J., Parker, P., Sahdra, B. K., \& Kashdan, T. B. (2015). Measures that make a difference: A functional contextualistic approach to optimizing psychological measurement in clinical research practice. In R.D. Zettle, S.C. Hayes, D. Barnes-Holmes, A. Biglan (Eds.), The Wiley handbook of contextual behavioral science (pp. 320-346). Malden, MA: Wiley Blackwell

Cohen, S., \& Syme, S. (1985). Social support and health. Cambridge, MA: Academic Press.

Cornelius, B. L., Groothoff, J. W., van der Klink, J. J., \& Brouwer, S. (2013). The performance of the K10, K6 and GHQ-12 to screen for present state DSM-IV 
disorders among disability claimants. BMC Public Health, 13, 128. doi:10.1186/14712458-13-128

Dahl, J., Wilson, K. G., \& Nilsson, A. (2004). Acceptance and commitment therapy and the treatment of persons at risk for long-term disability resulting from stress and pain symptoms: A preliminary randomized trial. Behavior Therapy, 35, 785-801. doi:10.1016/S0005-7894(04)80020-0

Davidson, R. J., Kabat-Zinn, J., Schumacher, J., Rosenkranz, M., Muller, D., Santorelli, S. F., ... Sheridan, J. F. (2003). Alterations in brain and immune function produced by mindfulness meditation. Psychosomatic Medicine, 65, 564-570. doi:10.1097/01.PSY.0000077505.67574.E3

Deci, E. L., \& Ryan, R. M. (1985). The general causality orientations scale: Selfdetermination in personality. Journal of Research in Personality, 19(2), 109-134. doi:10.1016/0092-6566(85)90023-6

Deci, E. L., \& Ryan, R. M. (2008). Self-determination theory: A macrotheory of human motivation, development, and health. Canadian Psychology/Psychologie canadienne, 49, 182-185. doi:10.1037/a0012801

Donath, S. (2001). The validity of the 12-item General Health Questionnaire in Australia: a comparison between three scoring methods. Australian and New Zealand Journal of Psychiatry, 35, 231-235. doi:10.1046/j.1440-1614.2001.00869.x

Easterlin, R. A. (2003). Building a better theory of well-being. Oxford: Oxford University Press.

Elphinstone, B., Sahdra, B. K., \& Ciarrochi, J. (2015). Living well by letting go: Reliability and validity of a brief measure of nonattachment. Unpublished manuscript.

Emmons, R. A. (1986). Personal strivings: An approach to personality and subjective wellbeing. Journal of Personality and Social Psychology, 51, 1058-1068. 
Endo, Y., Heine, S. J., \& Lehman, D. R. (2000). Culture and positive illusions in close relationships: How my relationships are better than yours. Personality and Social Psychology Bulletin, 26, 1571-1586. doi:10.1177/01461672002612011

Feinstein, L., \& Hammond, C. (2004). The contribution of adult learning to health and social capital. Oxford Review of Education, 30(2), 199-221. doi:10.1080/0305498042000215520

Ford, B. Q., \& Mauss, I. B. (2014). The paradoxical effects of pursuing positive emotion: When and why wanting to feel happy backfires. In J. Gruber \& J. Moskowitz (Eds.), Positive emotion: Integrating the light sides and dark sides (pp. 363-381). Oxford: Oxford University Press.

Fredrickson, B. L. (2001). The role of positive emotions in positive psychology: The broaden-and-build theory of positive emotions. American Psychologist, 56, 218-226. doi:10.1037/0003-066X.56.3.218

Gloster, A. T., Klotsche, J., Ciarrochi, J., Eifert, G., Sonntag, R., Wittchen, H.-U., \& Hoyer, J. (2017). Increasing valued behaviors precedes reduction in suffering: Findings from a randomized controlled trial using ACT. Behaviour Research and Therapy, 91, 6471. doi:10.1016/j.brat.2017.01.013

Goldberg, D. (1992). General health questionnaire (GHQ-12). Windsor, UK: Nfer-Nelson. Haack, M., \& Mullington, J. M. (2005). Sustained sleep restriction reduces emotional and physical well-being. Pain, 119, 56-64. doi:10.1016/j.pain.2005.09.011

Hayes, S. C., Strosahl, K. D., \& Wilson, K. G. (2011). Acceptance and commitment therapy: The process and practice of mindful change. New York, NY: Guilford Press.

Hooper, N., \& Larsson, A. (2015). The research journey of Acceptance and Commitment Therapy (ACT). London, UK: Palgrave Macmillan. 
Hu, L. T., \& Bentler, P. M. (1999). Cutoff criteria for fit indexes in covariance structure analysis: Conventional criteria versus new alternatives. Structural Equation Modeling: A Multidisciplinary Journal, 6, 1-55. doi:10.1080/10705519909540118

Huxhold, O., Miche, M., \& Schüz, B. (2013). Benefits of having friends in older ages: Differential effects of informal social activities on well-being in middle-aged and older adults. Journals of Gerontology Series B, 69, 366-375. doi:10.1093/geronb/gbt029

Jackson, D. L., Gillaspy Jr, J. A., \& Purc-Stephenson, R. (2009). Reporting practices in confirmatory factor analysis: An overview and some recommendations. Psychological Methods, 14, 6-23. doi:10.1037/a0014694

Jenkins, A. (2011). Participation in learning and wellbeing among older adults. International Journal of Lifelong Education, 30, 403-420. doi:10.1080/02601370.2011.570876

Jurakić, D., Pedišić, Ž., \& Greblo, Z. (2010). Physical activity in different domains and health-related quality of life: a population-based study. Quality of Life Research, 19, 1303-1309. doi:10.1007/s11136-010-9705-6

Kenny, D. A., Kaniskan, B., \& McCoach, D. B. (2014). The performance of RMSEA in models with small degrees of freedom. Sociological Methods \& Research, 44, 486507. doi:10.1177/0049124114543236

Keyes, C. L. (2006). Mental health in adolescence: is America's youth flourishing? American Journal of Orthopsychiatry, 76, 395-402. doi:10.1037/0002-9432.76.3.395

Kirkwood, T. B., Bond, J., May, C., McKeith, I., \& Teh, M. M. (2008). Foresight mental capital and wellbeing project. Wellbeing. doi:10.1002/9781118539415.wbwell092

Krueger, R. F., Hicks, B. M., \& McGue, M. (2001). Altruism and antisocial behavior: Independent tendencies, unique personality correlates, distinct etiologies. Psychological Science, 12, 397-402. doi:10.1111/1467-9280.00373 
Lansford, J. E., Antonucci, T. C., Akiyama, H., \& Takahashi, K. (2005). Quantitative and qualitative approach to social relationships and well-being in the United States and Japan. Journal of Comparative Family Studies, 36, 1-22.

Lundin, A., Hallgren, M., Theobald, H., Hellgren, C., \& Torgén, M. (2016). Validity of the 12-item version of the General Health Questionnaire in detecting depression in the general population. Public Health, 136, 66-74. doi:10.1016/j.puhe.2016.03.005

Lyubomirsky, S., King, L., \& Diener, E. (2005). The benefits of frequent positive affect:

Does happiness lead to success? Psychological Bulletin, 131, 803-855. doi:10.1037/0033-2909.131.6.803

Lyubomirsky, S., Sheldon, K. M., \& Schkade, D. (2005). Pursuing happiness: the architecture of sustainable change. Review of General Psychology, 9, 111.

Maher, J. P., Doerksen, S. E., Elavsky, S., Hyde, A. L., Pincus, A. L., Ram, N., \& Conroy, D. E. (2013). A daily analysis of physical activity and satisfaction with life in emerging adults. Health Psychology, 32, 647-656. doi:10.1037/a0030129

Martin, C. R., \& Newell, R. J. (2005). Is the 12-item General Health Questionnaire (GHQ-12) confounded by scoring method in individuals with facial disfigurement? Psychology \& Health, 20, 651-659. doi:10.1080/14768320500060061

Mazzucchelli, T. G., Kane, R. T., \& Rees, C. S. (2010). Behavioral activation interventions for well-being: A meta-analysis. Journal of Positive Psychology, 5(2), 105-121. doi:10.1080/17439760903569154

Mehnert, T., Krauss, H. H., Nadler, R., \& Boyd, M. (1990). Correlates of life satisfaction in those with disabling conditions. Rehabilitation Psychology, 35, 3-17. doi: $10.1037 / \mathrm{h} 0079046$

Morgan, K., \& Bath, P. A. (1998). Customary physical activity and psychological wellbeing: A longitudinal study. Age and Ageing, 27(S3), 35-40. 
Oswald, A. J., Proto, E., \& Sgroi, D. (2015). Happiness and productivity. Journal of Labor Economics, 33, 789-822. doi:10.1086/681096

Pickett, K., Yardley, L., \& Kendrick, T. (2012). Physical activity and depression: A multiple mediation analysis. Mental Health and Physical Activity, 5, 125-134. doi:10.1016/j.mhpa.2012.10.001

Poulin, M. J., Brown, S. L., Dillard, A. J., \& Smith, D. M. (2013). Does a helping hand mean a heavy heart? Helping behavior and well-being among spouse caregivers. Psychology and Aging, 25, 108-117. doi:10.1037/a0018064

Ratelle, C. F., Guay, F., Vallerand, R. J., Larose, S., \& Senécal, C. (2007). Autonomous, controlled, and amotivated types of academic motivation: A person-oriented analysis. Journal of Educational Psychology, 99, 734-746. doi:10.1037/0022-0663.99.4.734

Rowe, J. W., \& Kahn, R. L. (1998). Successful aging: The MacArthurfoundation study. New York, NY: Pantheon.

Ryan, R. M., \& Deci, E. L. (2017). Self-determination theory: Basic psychological needs in motivation, development, and wellness. New York, NY: Guilford Publications.

Sahdra, B. K., Ciarrochi, J., \& Parker, P. (2016). Nonattachment and mindfulness: Related but distinct constructs. Psychological Assessment.

Sahdra, B. K., Ciarrochi, J., Parker, P., Basarkod, G., Bradshaw, E., \& Baer, R. (2017). Are people mindful in different ways? Disentangling the quantity and quality of mindfulness in latent profiles and exploring their links to mental health and life effectiveness. European Journal of Personality, 31, 347-365. doi:10.1002/per.2108

Sahdra, B. K., Ciarrochi, J., Parker, P., Marshall, S., \& Heaven, P. (2015). Empathy and nonattachment independently predict peer nominations of prosocial behavior of adolescents. Frontiers in Psychology, 6, 263. doi:10.3389/fpsyg.2015.00263 
Sahdra, B. K., Ciarrochi, J., Parker, P., \& Scrucca, L. (2016). Using genetic algorithms in a large nationally representative American sample to abbreviate the Multidimensional Experiential Avoidance Questionnaire. Frontiers in Psychology, 7, 189. doi:10.3389/fpsyg.2016.00189

Sahdra, B. K., Shaver, P. R., \& Brown, K. W. (2010). A scale to measure nonattachment: A Buddhist complement to Western research on attachment and adaptive functioning. Journal of Personality Assessment, 92(2), 116-127. doi:10.1080/00223890903425960

Schwartz, C., Meisenhelder, J. B., Ma, Y., \& Reed, G. (2003). Altruistic social interest behaviors are associated with better mental health. Psychosomatic Medicine, 65, 778785. doi:10.1097/01.PSY.0000079378.39062.D4

Sheldon, K. M., \& Kasser, T. (1995). Coherence and congruence: Two aspects of personality integration. Journal of Personality and Social Psychology, 68, 531-543.

Team, R. C. (2015). A language and environment for statistical computing. Vienna, Austria.

Wilson, K. G., Sandoz, E. K., Kitchens, J., \& Roberts, M. (2010). The Valued Living Questionnaire: Defining and measuring valued action within a behavioral framework. The Psychological Record, 60, 249-272. doi:10.1007/bf03395706 


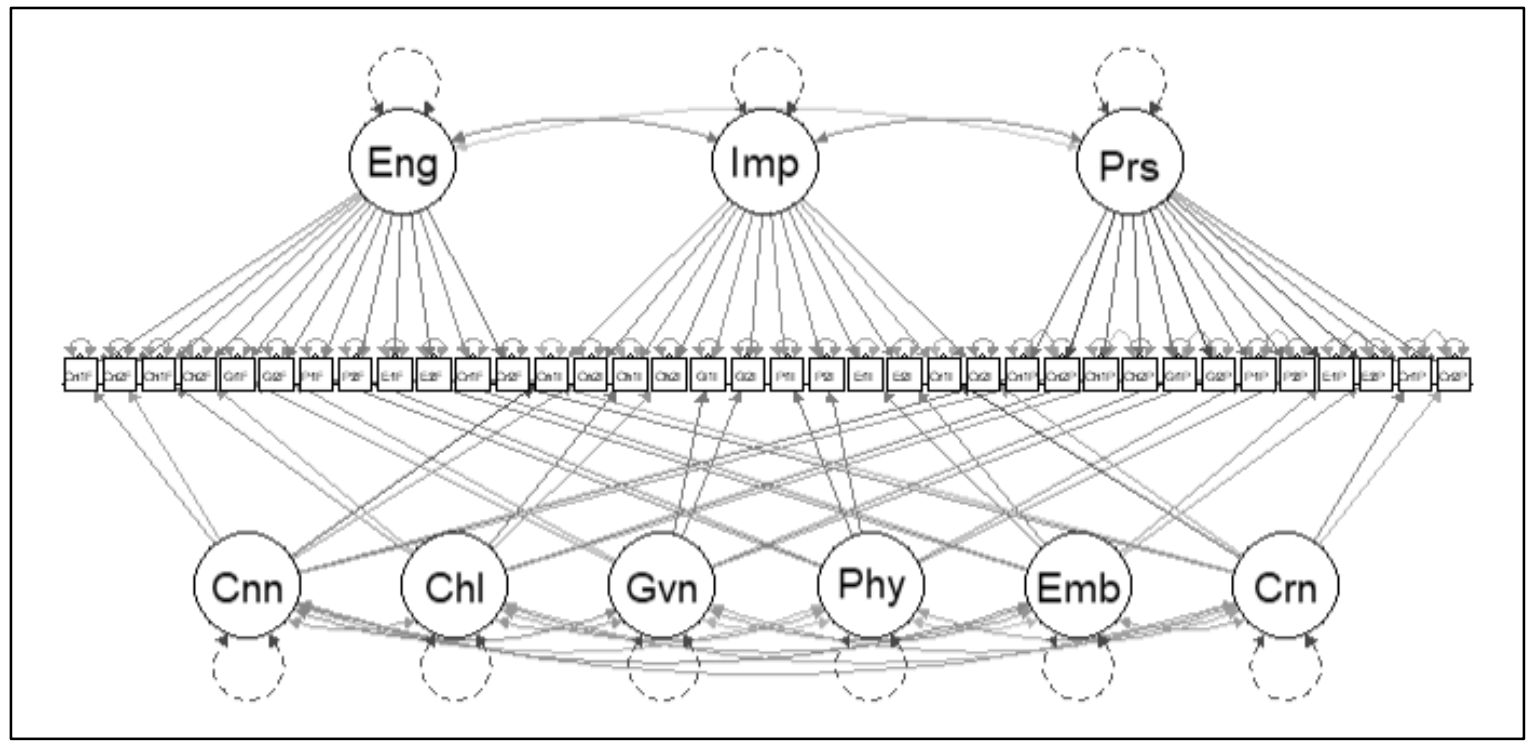

Figure 1. Bifactor model of the Six Ways to Well-Being

Note. Eng = behaviour engagement Imp = activity importance; Prs = activity pressure; $\mathrm{Cnn}=$ connecting with others; $\mathrm{Chl}=$ challenging oneself; $\mathrm{Gvn}=$ giving to others; Phy $=$ engaging in physical activity; Emb = embracing the moment; $\mathrm{Crn}=$ caring for oneself 

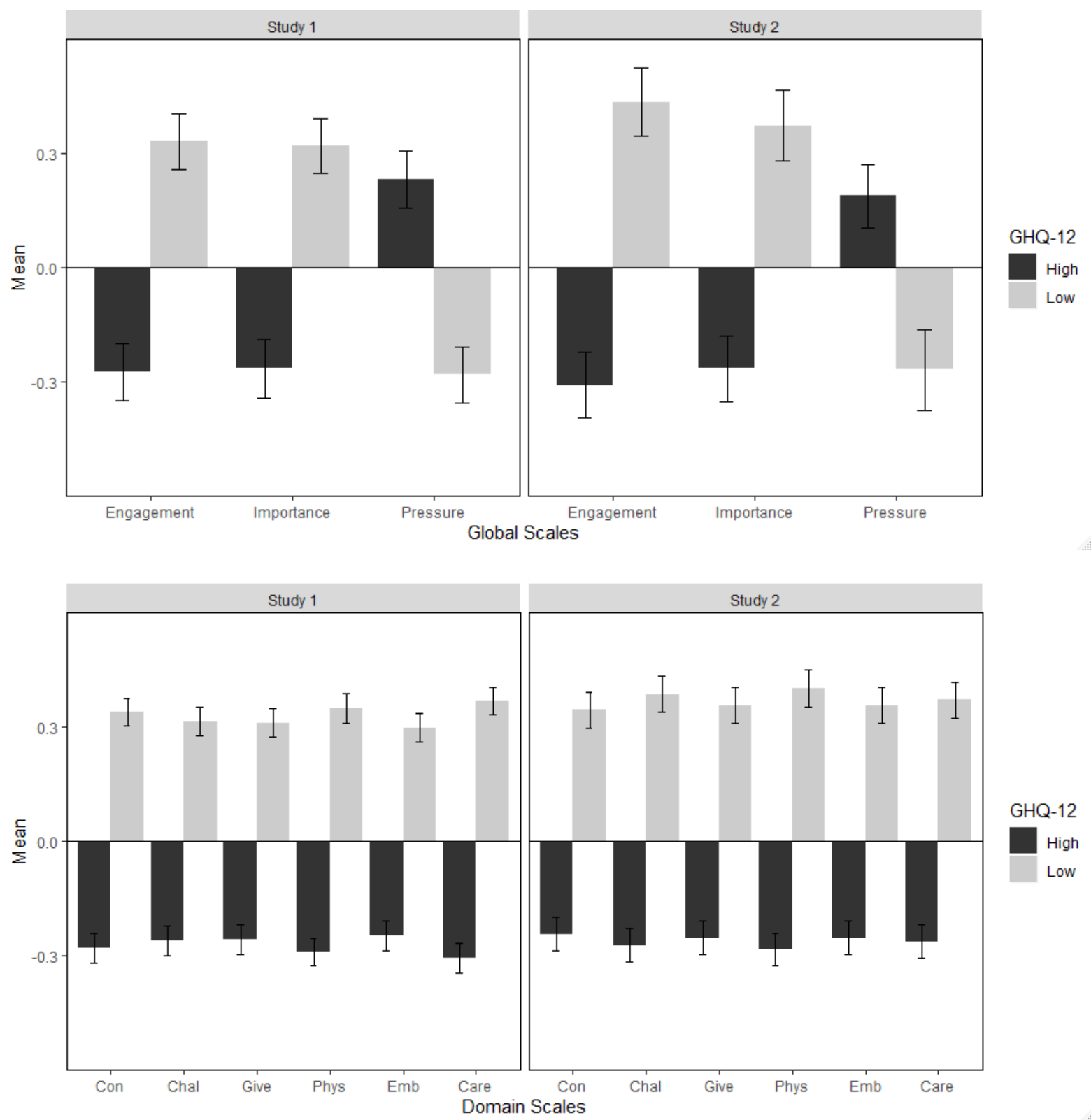

Figure 2. Bar plots with $95 \%$ confidence intervals comparing subgroups of participants who scored $\geq 12$ on the General Health Questionnaire-12 and those who scored $\leq 11$, for Studies 1 and 2. Top panel presents standardised scale scores for global subscales of the $6 \mathrm{~W}-\mathrm{WeB}$ and the bottom panel shows standardised scale scores for domain subscales of the $6 \mathrm{~W}-\mathrm{WeB}$. Note . Engagement = behaviour engagement; Importance $=$ activity importance; Pressure $=$ activity pressure Con $=$ connecting with others Chal $=$ challenging oneself; Give $=$ giving to others; Phys = engaging in physical activity $; \mathrm{Emb}=$ embracing the moment Care $=$ caring for oneself. 
Table 1

Demographic Information for Samples From Studies 1 and 2.

\begin{tabular}{|c|c|c|}
\hline & Study 1 & Study 2 \\
\hline Total N & 1800 & 855 \\
\hline \multicolumn{3}{|l|}{ Ethnicity (\%) } \\
\hline Caucasians & 66.9 & 74 \\
\hline African American & 10.2 & - \\
\hline Hispanic & 10.2 & - \\
\hline Asian & - & 15.9 \\
\hline Indigenous Australians/New Zealanders & - & 2.7 \\
\hline Other & 12.8 & 7.4 \\
\hline Income $(\%)$ & (USD) & (AUD) \\
\hline$<20,000$ & 18.6 & 8.9 \\
\hline $20,001-60,000$ & 46 & 35.9 \\
\hline $60,001-100,000$ & 24.2 & 31.9 \\
\hline$>100,000$ & 11.1 & 23.3 \\
\hline Other & 0.2 & - \\
\hline \multicolumn{3}{|l|}{ Education (\%) } \\
\hline High School & 24.2 & 33.1 \\
\hline College Diploma & 58 & 32.3 \\
\hline Graduate Degree & 17.8 & 34.6 \\
\hline
\end{tabular}


Table 2

Alpha reliability estimates of the $6 W$-WeB subscales and the zero-order correlations between the scale scores of the $6 W-W e B$ subscales and scale scores of criterion variables in Study 1.

\begin{tabular}{llllllllll}
\hline & Eng & Imp & Pres & Con & Chal & Give & Phys & Emb & Care \\
\hline$\alpha$ & .90 & .88 & .94 & .77 & .76 & .75 & .76 & .77 & .76 \\
Emo F & $.40^{* * *}$ & $.33^{* * *}$ & $-.11^{*}$ & $.28^{* * *}$ & $.29^{* * *}$ & $.26^{* * *}$ & $.31^{* * *}$ & $.24^{* * *}$ & $.24^{* * *}$ \\
Psych F & $.44^{* * * *}$ & $.34^{* * *}$ & $-.14^{* *}$ & $.31^{* * *}$ & $.31^{* * *}$ & $.28^{* * *}$ & $.35^{* * *}$ & $.25^{* * *}$ & $.28^{* * *}$ \\
Soc F & $.42^{* * *}$ & $.22^{* * *}$ & .07 & $.15^{* * *}$ & $.22^{* * *}$ & $.12^{* *}$ & $.25^{* * *}$ & $.10^{*}$ & $.14^{* *}$ \\
GHQ-12 & $-.31^{* * *}$ & $-.27^{* * *}$ & $.30^{* * *}$ & $-.33^{* * *}$ & $-.32^{* * *}$ & $-.28^{* * *}$ & $-.35^{* * *}$ & $-.28^{* * *}$ & $-.35^{* * *}$ \\
BehAvd & .01 & -.08 & $.31^{* * *}$ & $-.15^{* * *}$ & $-.17^{* * *}$ & $-.17^{* * *}$ & $-.15^{* *}$ & $-.20^{* * *}$ & $-.18^{* * *}$ \\
DisAver & .03 & -.05 & $.28^{* * *}$ & $-.11^{*}$ & $-.12^{* *}$ & $.09^{*}$ & $-.09^{*}$ & $-.18^{* * *}$ & $-.19^{* * *}$ \\
DstSup & $.22^{* * *}$ & $.15^{* * *}$ & .00 & $.13^{* *}$ & $.19^{* * *}$ & $.13^{* *}$ & .07 & $.11^{*}$ & .07 \\
RepDen & .02 & $-.17^{* * *}$ & $.49^{* * *}$ & $-.33^{* * *}$ & $-.20^{* * *}$ & $-.27^{* * *}$ & $-.22^{* * *}$ & $-.35^{* * *}$ & $-.31^{* * * *}$ \\
Procst & $-.23^{* * *}$ & $-.23^{* * *}$ & $.38^{* * *}$ & $-.33^{* * *}$ & $-.35^{* * *}$ & $-.29^{* * *}$ & $-.31^{* * *}$ & $-.29^{* * *}$ & $-.31^{* * *}$ \\
DisEndr & $.40^{* * * *}$ & $.39^{* * *}$ & $-.24^{* * *}$ & $.38^{* * *}$ & $.41^{* * *}$ & $.32^{* * *}$ & $.32^{* * *}$ & $.37^{* * *}$ & $.31^{* * *}$ \\
NAS-7 & $.43^{* * *}$ & $.50^{* * *}$ & $-.24^{* * *}$ & $.44^{* * *}$ & $.42^{* * *}$ & $.42^{* * *}$ & $.33^{* * *}$ & $.37^{* * * *}$ & $.40^{* * *}$ \\
\hline Note. Keyes & & & & & & & & & \\
\hline
\end{tabular}

Note. Keyes' flourishing measure subscales: Emo F = emotional, Psych F = psychological, Soc F = social; GHQ-12 = General Health Questionnaire-12; Multidimensional Experiential Avoidance Subscale -30 subscales: BehAvd $=$ behavioural avoidance, DisAver $=$ distress aversion, DstSup $=$ distraction and suppression, RepDen $=$ repression/denial, Procst $=$ procrastination subscale, DisEndr $=$ distress endurance; NAS-7 $=$ Nonattachment Scale -7. Eng $=$ behaviour engagement Imp = activity importance; Pres $=$ activity pressure $;$ Con $=$ connecting with others; Chal $=$ challenging oneself; Give $=$ giving to others; Phys $=$ engaging in physical activity; Emb = embracing the moment; Care $=$ caring for oneself. ${ }^{*} p<.05 . * * p<.01 . * * * p<.001$. 
Table 3

Alpha reliability estimates of the $6 \mathrm{~W}$-WeB subscales and the zero-order correlations between the scale scores of the $6 \mathrm{~W}-\mathrm{WeB}$ and scale scores of criterion variables in Study 2.

\begin{tabular}{llllllllll}
\hline & Eng & Imp & Pres & Con & Chal & Give & Phys & Emb & Care \\
\hline$\alpha$ & .90 & .89 & .94 & .77 & .76 & .80 & .74 & .77 & .75 \\
Emo F & $.41^{* * *}$ & $.34^{* * *}$ & $-.12^{* * *}$ & $.30^{* * *}$ & $.30^{* * *}$ & $.26^{* * *}$ & $.32^{* * *}$ & $.24^{* * *}$ & $.28^{* * *}$ \\
Psych F & $.46^{* * *}$ & $.39^{* * *}$ & $-.17^{* * *}$ & $.37^{* * *}$ & $.35^{* * *}$ & $.32^{* * *}$ & $.35^{* * *}$ & $.30^{* * *}$ & $.32^{* * *}$ \\
Soc F & $.38^{* * *}$ & $.27^{* * *}$ & .05 & $.20^{* * *}$ & $.20^{* * *}$ & $.16^{* * *}$ & $.27^{* * *}$ & $.09^{* *}$ & $.17^{* * *}$ \\
GHQ-12 & $-.38^{* * * *}$ & $-.27^{* * *}$ & $.20^{* * *}$ & $-.28^{* *}$ & $-.33^{* * *}$ & $-.25^{* * *}$ & $-.31^{* * *}$ & $-.26^{* * *}$ & $-.31^{* * *}$ \\
\hline
\end{tabular}

Note. Keyes' flourishing measure subscales: Emo F = emotional, Psych F = psychological, Soc F = social; GHQ-12 = General Health Questionnaire-12.

Eng = behaviour engagement Imp = activity importance Pres = activity pressure Con = connecting with others; Chal $=$ challenging oneself; Give $=$ giving to others; Phys = engaging in physical activity; Emb = embracing the moment; Care = caring for oneself $* p<.05 . * * p<.01 . * * * p<.001$. 
Table 4

Alpha reliability estimates of the $6 \mathrm{~W}$-WeB subscales and the zero-order correlations between the scale scores of the $6 W-W e B$ and scale scores of criterion variables in Study 3.

\begin{tabular}{llllllllll}
\hline & Eng & Imp & Pres & Con & Chal & Give & Phys & Emb & Care \\
\hline$\alpha$ & .85 & .86 & .91 & .82 & .79 & .79 & .75 & .81 & .73 \\
Emo F & $.41^{* * *}$ & $.33^{* * *}$ & $-.25^{* * *}$ & $.32^{* * *}$ & $.32^{* * *}$ & $.27^{* * *}$ & $.35^{* * *}$ & $.26^{* * *}$ & $.30^{* * * *}$ \\
Psych F & $.43^{* * * *}$ & $.34^{* * *}$ & $-.24^{* * *}$ & $.34^{* * *}$ & $.35^{* * *}$ & $.28^{* * *}$ & $.36^{* * *}$ & $.23^{* * *}$ & $.27^{* * *}$ \\
Soc F & $.41^{* * *}$ & $.33^{* * *}$ & $-.22^{* * *}$ & $.33^{* *}$ & $.31^{* * *}$ & $.27^{* * *}$ & $.34^{* * *}$ & $.21^{* * *}$ & $.29^{* * *}$ \\
NAS-7 & $.42^{* * *}$ & $.39^{* * *}$ & $-.34^{* * *}$ & $.35^{* * *}$ & $.37^{* * *}$ & $.39^{* * *}$ & $.39^{* * *}$ & $.36^{* * *}$ & $.29^{* * * *}$ \\
\hline
\end{tabular}

Note. Keyes' flourishing measure subscales: Emo F = emotional, Psych F = psychological, Soc F = social flourishing; NAS-7 = Nonattachment Scale -7 ;

Eng = behaviour engagement Imp = activity importance; Pres = activity pressure Con = connecting with others; Chal $=$ challenging oneself ; Give $=$ giving to others; Phys $=$ engaging in physical activity; Emb = embracing the moment; Care = caring for oneself $* p<.05 . * * p<.01 . * * * p<.001$. 
Table 5

Summary of goodness of fit for measurement invariance structural equation models of the Six Ways to Well-Being final bifactor model (including modification indices) across gender, age, and countries, in the combined sample.

\section{Chi square df $\quad$ CFI TLI RMSEA [90\% CI]}

Age

Step 1: Configural invariance $\quad 4250.99 \quad 1068 \quad .92 \quad .91 \quad .043\left[\begin{array}{llll}.042 & .044\end{array}\right]$

Step 2: Loadings invariance $\quad 4349.20 \quad 1131 \quad .92 \quad .91 \quad .042\left[\begin{array}{llll}.041 & .043\end{array}\right]$

Step 3: Intercepts invariance $\quad 4430.42 \quad 1158 \quad .92 \quad .91 \quad .042\left[\begin{array}{llll}.041 & .043\end{array}\right]$

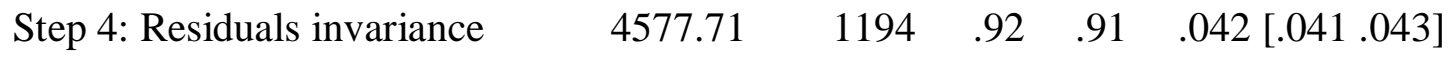

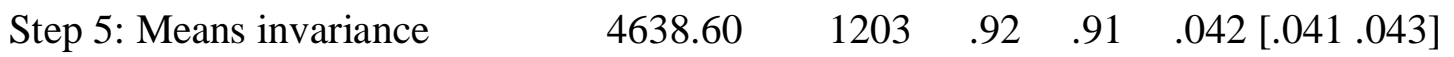

Gender

Step 1: Configural invariance $\quad 4330.15 \quad 1068 \quad .92 \quad .91 \quad .044\left[\begin{array}{llll}.043 & .045\end{array}\right]$

$\left.\begin{array}{llllll}\text { Step 2: Loadings invariance } & 4369.29 & 1131 & .92 & .91 & .043\end{array}\right]$

$\left.\begin{array}{llllll}\text { Step 3: Intercepts invariance } & 4462.22 & 1158 & .92 & .91 & .042\end{array}\right]\left[\begin{array}{lll}.041 & .044\end{array}\right]$

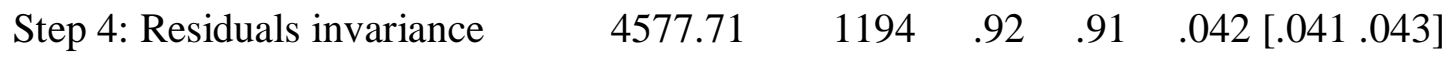

$\left.\begin{array}{llllll}\text { Step 5: Means invariance } & 4638.60 & 1203 & .92 & .91 & .042\end{array}\right]$

Country

$\begin{array}{llllll}\text { Step 1: Configural invariance } & 4160.32 & 1068 & .93 & .91 & .043\end{array}\left[\begin{array}{lll}.042 & .044\end{array}\right]$

$\left.\begin{array}{llllll}\text { Step 2: Metric invariance } & 4348.61 & 1131 & .92 & .92 & .042\end{array}\right]\left[\begin{array}{llll}.041 & .043\end{array}\right]$

$\left.\begin{array}{llllll}\text { Step 3: Scalar invariance } & 4424.73 & 1158 & .92 & .92 & .042\end{array}\right]$

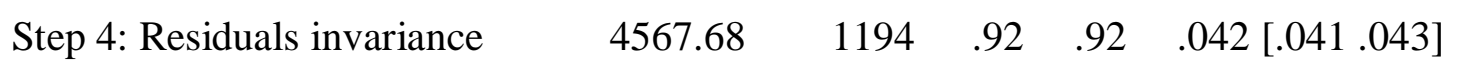

$\left.\begin{array}{llllll}\text { Step 5: Means invariance } & 4524.25 & 1203 & .92 & .92 & .042\end{array}\right]\left[\begin{array}{llll}.041 & .043\end{array}\right]$

Note. CFI = comparative fit index; TLI = Tucker Lewis index; RMSEA = root mean square error of approximation; $\mathrm{CI}=$ confidence interval. 


\section{Supplementary Materials 1A:}

\section{The Six Ways to Well-Being Questionnaire}

\section{Life Activity Survey}

\section{Instructions:}

You will be asked a series of questions about the activities you engage in. To answer these questions, please focus on behaviours that:

1) You typically engage in.

2) Are observable from the outside.

3) You actually engage in, rather than those you think you should engage in.

You will first be asked to report examples of behaviours, after which you will be asked to rate each of these on three scales. Please select a number from 1 to 6 on these scales to rate the extent to which you agree with it. 
CON: Typical ways in which I connect with others.

Think of the typical ways in which you connect with the people around you. How do you connect with family, friends, neighbours, community groups, or other people?

Examples: having conversations, interacting on the internet, doing activities together, celebrating, going out together, etc.

1. Here is an example of how I typically connect with others:

a) I am satisfied with how frequently I do this. 1 2 3

Disagree Disagree Disagree Strongly Moderately Slightly 4 Agree 5 Agree Slightly Moderately

\section{6}

Agree Strongly

b) This is personally important or enjoyable. I do it because I want to do it.

$$
1
$$

Disagree

Strongly
Disagree Moderately
3

Disagree

Slightly

4

Agree Slightly
Agree

Moderately
Agree

Strongly

c) I feel pressured to do this (e.g., from others or from a sense of guilt). 1

Disagree Strongly

\section{2}

Disagree Moderately
3

Disagree Slightly
4

Agree

Slightly

\section{5}

Agree Moderately

\section{6}

Agree Strongly

2. Here is a second example of how I typically connect with others:

a) I am satisfied with how frequently I do this.

1

Disagree

Strongly
2

Disagree

Moderately
3

Disagree

Slightly
4

Agree

Slightly

\section{5}

Agree

Moderately
6

Agree

Strongly

b) This is personally important or enjoyable. I do it because I want to do it.

1

Disagree

Strongly

\section{2}

Disagree

Moderately
3

Disagree

Slightly

\section{4}

Agree

Slightly

\section{5}

Agree

Moderately
6

Agree

Strongly

c) I feel pressured to do this (e.g., from others or from a sense of guilt). 1

Disagree

Strongly

\section{2}

Disagree Moderately
3

Disagree Slightly

\section{4}

Agree

Slightly
Agree Moderately

\section{6} Agree Strongly 
CHAL: Typical ways in which I challenge myself.

Think of the typical ways in which you challenge yourself and learn new things.

Examples: Trying something new, learning a musical instrument, trying to cook your favorite food, fixing something, developing your skills, taking on new responsibilities, signing up for an online course, etc.

1. Here is an example of how I typically challenge myself:

a) I am satisfied with how frequently I do this. 1 2 3

Disagree Disagree Disagree Strongly Moderately Slightly 4 Agree 5 Agree Slightly Moderately

\section{6}

Agree

Strongly

b) This is personally important or enjoyable. I do it because I want to do it.

$$
1
$$

Disagree

Strongly
Disagree Moderately
3

Disagree

Slightly

4

Agree Slightly
Agree

Moderately
Agree Strongly

c) I feel pressured to do this (e.g., from others or from a sense of guilt). 1

Disagree Strongly
2

Disagree Moderately
3

Disagree Slightly
4

Agree

Slightly

\section{5}

Agree Moderately

\section{6}

Agree Strongly

2. Here is a second example of how I typically challenge myself:

a) I am satisfied with how frequently I do this.

$\begin{array}{llll}1 & 2 & 3 & 4\end{array}$

Disagree

Disagree

Disagree

Agree

5

6

Strongly Moderately

Slightly

Slightly

Agree

Agree

b) This is personally important or enjoyable. I do it because I want to do it. 1

Disagree

Strongly

\begin{abstract}
2
\end{abstract}
Disagree Moderately
3

Disagree

Slightly
4

Agree

Slightly

\section{5}

Agree

Moderately
6

Agree

Strongly

c) I feel pressured to do this (e.g., from others or from a sense of guilt). 1

Disagree

Strongly

\section{2}

Disagree Moderately
3

Disagree

Slightly
4

Agree

Slightly
5

Agree

Moderately
6 Agree Strongly 
GIVE: Typical ways in which I give to others.

Think of the typical ways in which you give to and/or help others.

Examples: Helping someone to do something, volunteering, making a donation, doing something kind for a friend or stranger, working for a cause, etc.

1. Here is an example of how I typically give to others:

a) I am satisfied with how frequently I do this.

1

Disagree

Strongly

\section{2}

Disagree

Moderately
3

Disagree

Slightly
4

Agree

Slightly

\section{5}

Agree

Moderately
6

Agree

Strongly

b) This is personally important or enjoyable. I do it because I want to do it. 1

Disagree

Strongly

\section{2}

Disagree

Moderately
3

Disagree

Slightly

\section{4}

Agree

Slightly
5

Agree

Moderately
6

Agree

Strongly

c) I feel pressured to do this (e.g., from others or from a sense of guilt).

1

Disagree

Strongly
2

Disagree Moderately
3

Disagree

Slightly
4

Agree

Slightly
Agree Moderately

\section{6}

Agree Strongly

2. Here is a second example of how I typically give to others:

a) I am satisfied with how frequently I do this.

1

Disagree

Strongly
2

Disagree

Moderately

\section{3}

Disagree

Slightly
4

Agree

Slightly
5

Agree

Moderately
6

Agree

Strongly

b) This is personally important or enjoyable. I do it because I want to do it.

1

Disagree

Strongly
2

Disagree

Moderately
3

Disagree

Slightly
Agree

Slightly
Agree

Moderately
6 Agree Strongly

c) I feel pressured to do this (e.g., from others or from a sense of guilt). 1

Disagree

Strongly

\section{2}

Disagree

Moderately
3

Disagree

Slightly

\section{4}

Agree

Slightly
5

Agree

Moderately

\section{6}

Agree

Strongly 
PHYS: Typical ways in which I engage in physical activity.

Think of the typical ways in which you engage in physical activities.

Examples: Going for a walk or a jog, cycling, going to the gym, dancing, playing sports with friends, etc.

1. Here is an example of how I typically engage in physical activity:

a) I am satisfied with how frequently $I$ do this.

1

Disagree

Strongly

\section{2}

Disagree

Moderately
3

Disagree

Slightly
4

Agree

Slightly

\section{5}

Agree

Moderately
6

Agree

Strongly

b) This is personally important or enjoyable. I do it because I want to do it. 1

Disagree

Strongly

\section{2}

Disagree

Moderately
3

Disagree

Slightly

\section{4}

Agree

Slightly

\section{5}

Agree

Moderately
6

Agree

Strongly

c) I feel pressured to do this (e.g., from others or from a sense of guilt). 1

Disagree Strongly
2

Disagree Moderately
3

Disagree Slightly
4

Agree Slightly
Agree Moderately

\section{6}

Agree Strongly

2. Here is a second example of how I typically engage in physical activity:

a) I am satisfied with how frequently I do this.

1

Disagree

Strongly

\section{2}

Disagree

Moderately

\section{3}

Disagree

Slightly

\section{4}

Agree

Slightly

\section{5}

Agree

Moderately
6

Agree

Strongly

b) This is personally important or enjoyable. I do it because I want to do it. 1

Disagree

Strongly

\begin{abstract}
2
\end{abstract}
Disagree Moderately
3

Disagree

Slightly
4

Agree

Slightly

\section{5}

Agree

Moderately
6

Agree

Strongly

c) I feel pressured to do this (e.g., from others or from a sense of guilt). 1

Disagree

Strongly

\section{2}

Disagree Moderately
3

Disagree

Slightly
4

Agree

Slightly
5

Agree Moderately
6 Agree Strongly 
EMB: Typical ways in which I embrace the moment.

Think of the typical ways in which you get fully involved in the present moment.

Examples: Being curious, catching sight of something beautiful, noticing something unusual, enjoying and appreciating food, paying full attention to another person, and, in general noticing the world around you and what you are feeling. Just about any activity can involve embracing the moment.

1. Here is an example of how I typically embrace the moment:

a) I am satisfied with how frequently I do this.

$\begin{array}{lllllll}1 & 2 & 3 & 4 & 5 & 6\end{array}$

Disagree Disagree Disagree Agree Agree Agree

Strongly Moderately Slightly Slightly Moderately Strongly

b) This is personally important or enjoyable. I do it because I want to do it.

1

Disagree

Strongly
2

Disagree Moderately
3

Disagree

Slightly
4

Agree

Slightly
5

Agree

Moderately
6

Agree

Strongly

c) I feel pressured to do this (e.g., from others or from a sense of guilt). 1 2 3

\section{4}

\section{5} 6

Disagree

Disagree

Disagree

Strongly

Moderately

Slightly

Agree

Agree

Slightly

Moderately

Agree

Strongly

2. Here is a second example of how I typically embrace the moment:

a) I am satisfied with how frequently I do this.

1

Disagree

Strongly
2

Disagree

Moderately
3

Disagree

Slightly

\section{4}

Agree

Slightly

\section{5}

Agree

Moderately
6

Agree

Strongly

b) This is personally important or enjoyable. I do it because I want to do it.

1

Disagree

Strongly

\section{2}

Disagree

Moderately
3

Disagree

Slightly

\section{4}

Agree

Slightly

\section{5}

Agree

Moderately
6

Agree

Strongly

c) I feel pressured to do this (e.g., from others or from a sense of guilt).

1

Disagree

Strongly
2

Disagree

Moderately
3

Disagree

Slightly

\section{4}

Agree

Slightly
Agree

Moderately

\section{6}

Agree

Strongly 
CARE: Typical ways in which I care for myself.

Think of the typical ways in which you care for yourself.

Examples: Maintaining a healthy diet, getting enough sleep or doing something relaxing after a hard day.

1. Here is an example of how I typically care for myself:

a) I am satisfied with how frequently I do this.

$\begin{array}{lllllll}1 & 2 & 3 & 4 & 5 & 6\end{array}$

Disagree Disagree Disagree Agree Agree Agree

Strongly Moderately Slightly Slightly Moderately Strongly

b) This is personally important or enjoyable. I do it because I want to do it.

1

Disagree

Strongly
2

Disagree Moderately
3

Disagree

Slightly
4

Agree

Slightly
Agree

Moderately
6

Agree

Strongly

c) I feel pressured to do this (e.g., from others or from a sense of guilt). 1 2 3 4 5 6

Disagree Disagree Disagree Strongly Moderately Slightly Agree Agree Slightly Moderately

2. Here is a second example of how I typically care for myself:

a) I am satisfied with how frequently I do this. 1

Disagree Strongly

\section{2}

Disagree Moderately
3

Disagree

Slightly

\section{4}

Agree

Slightly

\section{5}

Agree Moderately

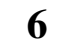

Agree Strongly

b) This is personally important or enjoyable. I do it because I want to do it. 1

Disagree

Strongly

\section{2}

Disagree

Moderately
3

Disagree

Slightly

\section{4}

Agree

Slightly

\section{5}

Agree

Moderately
6 Agree

Strongly

c) I feel pressured to do this (e.g., from others or from a sense of guilt). 1

Disagree

Strongly
2

Disagree Moderately
3

Disagree Slightly
4

Agree Slightly
Agree Moderately

\section{6}

Agree

Strongly 


\section{Other behaviours I engage in (Optional).}

Is there any other activity that you engage in, that does not fit into any of the previously mentioned categories:

1) Connecting with Others

2) Challenging Myself

3) Giving to Others

4) Being Physically Active

5) Embracing the Moment

6) Caring for Myself.

If so, please describe this 'other' behaviour below and rate it on the same three scales as before.

Another behaviour that I typically engage in:

$\begin{array}{ccccccc}\text { a) I am satisfied with how frequently I do this. } & & & \\ \mathbf{1} & \mathbf{2} & \mathbf{3} & \mathbf{4} & \mathbf{5} & \mathbf{6} \\ \text { Disagree } & \text { Disagree } & \text { Disagree } & \text { Agree } & \text { Agree } & \text { Agree } \\ \text { Strongly } & \text { Moderately } & \text { Slightly } & \text { Slightly } & \text { Moderately } & \text { Strongly }\end{array}$

b) This is personally important or enjoyable. I do it because I want to do it.

1

Disagree

Strongly
2

Disagree

Moderately
3

Disagree

Slightly
5

Agree

Agree

Slightly

Moderately

Agree

c) I feel pressured to do this (e.g., from others or from a sense of guilt).

1

Disagree

Strongly
2

Disagree

Moderately
3

Disagree

Slightly
4

Agree

Slightly
5

Agree Moderately
6

Agree

Strongly 


\section{Supplementary Material 1B:}

\section{Six Ways to Well-Being Questionnaire Description and Scoring Instructions}

\section{Scale description:}

This is a measure that assesses valued activity in 6 behavioural domains: Connecting with Others, Challenging Oneself, Giving to Others, Physical Activity, Embracing the Moment, and Self-Care.

Connecting with Others: This is how you connect with the people around you (such as family, friends, neighbours, or community groups).

Examples: having conversations, interacting on the internet, doing activities together, celebrating, going out together, etc.

Challenging Oneself: This is how you challenge yourself and learn new things.

Examples: Trying something new, learning a musical instrument, trying to cook your favorite food, fixing something, developing your skills, taking on new responsibilities, signing up for an online course, etc.

Giving to Others: This is how you give to others or help others.

Examples: Helping someone to do something, volunteering, making a donation, doing something kind for a friend or stranger, working for a cause, etc.

Physical Activity: This is how you engage in physical activity/exercise.

Examples: Going for a walk or a jog, cycling, going to the gym, dancing, playing sports with friends, etc.

Embracing the Moment: This is how you get fully involved in the present moment.

Examples: Being curious, catching sight of something beautiful, noticing something unusual, enjoying and appreciating food, paying full attention to another person, and, in general noticing the world around you and what you are feeling. Just about any activity can involve embracing the moment.

Self-Care: This is how you care for yourself.

Examples: Maintaining a healthy diet, getting enough sleep or doing something relaxing after a hard day.

For each of the six domains, respondents will need to report two examples of the typical ways in which they engage with that behaviour domain. Each example, then, has to be rated on three scales: satisfaction with the frequency of behavioural engagement, autonomous motivation (or importance), and controlled motivation (or pressure). 
Initial analysis has revealed the measure to fit well to a bi-factor CFA model. This means that each of the 36 items ( 2 examples x 3 rating scales x 6 domains) will load on one global factor as well as one domain factor. The 3 rating scales form the global factors of Frequency, Importance, and Pressure. The 6 domains of behaviour form the 6 domain factors.

\section{Scoring:}

The global factors are scored by taking the mean of all items of that scale.

E.g., the Frequency factor is scored by taking the mean of items: CON 1a, CON 2a, CHAL 1a, CHAL 2a, GIVE 1a, GIVE 2a, PHYS 1a, PHYS 2a, EMB 1a, EMB 2a, CARE 1a, CARE $2 \mathrm{a}$.

The importance factor is scored by averaging items $1 \mathrm{~b}$ and $2 \mathrm{~b}$ for each example, and the pressure factor is scored with items $1 \mathrm{c}$ and $2 \mathrm{c}$.

To score the domain factors, all pressure items need to first be reverse scored ( 7 - item score $=$ reverse score). Each of the domain factors are scored by taking the mean of the frequency, importance, and reverse-scored pressure items for that domain.

E.g., the Connecting factor is scored by averaging: CON 1a, CON 2a, CON 1b, CON 2b, CON 3a (reversed), CON 3b (reversed). 


\section{Supplementary Material 2:}

\section{Modification Indices}

Table S1

Top 20 modification indices from the 6W-WeB bifactor model in Study 1.

\begin{tabular}{|c|c|c|c|}
\hline Item $_{1}$ & Operation & Item $_{2}$ & Scaled modification index \\
\hline Emb1Pres & $\sim \sim$ & Emb2Pres & 157.60 \\
\hline Care2Freq & $\sim \sim$ & Care2Imp & 125.94 \\
\hline Care2Imp & $\sim \sim$ & Care2Pres & 103.71 \\
\hline Chal2Freq & $\sim \sim$ & Chal2Imp & 99.39 \\
\hline Con2Imp & $\sim \sim$ & Con2Pres & 90.94 \\
\hline Care1Pres & $\sim \sim$ & Care2Pres & 82.67 \\
\hline Phys1Pres & $\sim \sim$ & Phys2Pres & 78.52 \\
\hline Emb2Freq & $\sim \sim$ & Emb1Imp & 73.80 \\
\hline Chal2Imp & $\sim \sim$ & Chal2Pres & 71.49 \\
\hline Give2Imp & $\sim \sim$ & Give2Pres & 70.90 \\
\hline Con1Pres & $\sim \sim$ & Con2Pres & 67.32 \\
\hline Con1Imp & $\sim \sim$ & Con2Pres & 64.94 \\
\hline Phys2Imp & $\sim \sim$ & Phys2Pres & 64.40 \\
\hline Give1Imp & $\sim \sim$ & Give2Pres & 63.82 \\
\hline Phys2Freq & $\sim \sim$ & Phys2Imp & 62.43 \\
\hline Give1Pres & $\sim \sim$ & Give2Pres & 61.69 \\
\hline Con2Freq & $\sim \sim$ & Con2Imp & 60.66 \\
\hline Phys1Freq & $\sim \sim$ & Phys1Imp & 57.76 \\
\hline Give1Imp & $\sim \sim$ & Give1Pres & 54.45 \\
\hline Give1Freq & $\sim \sim$ & Give1Imp & 54.34 \\
\hline
\end{tabular}

Note. The ' $\sim$ ' operation indicates a residual covariance between Item 1 and Item $_{2}$. 


\section{Supplementary Material 3:}

\section{Factor Loadings}

Table S2

Factor loadings for each factor of the Six Ways to Well-Being using the combined sample.

\begin{tabular}{|c|c|c|c|c|c|c|c|c|c|}
\hline & Eng & Imp & Pres & Con & Chal & Give & Phys & Emb & Care \\
\hline Con1Freq & .57 & & & .52 & & & & & \\
\hline Con2Freq & .65 & & & .36 & & & & & \\
\hline Chal1Freq & .59 & & & & .51 & & & & \\
\hline Chal2Freq & .68 & & & & .33 & & & & \\
\hline Give1Freq & .55 & & & & & .48 & & & \\
\hline Give2Freq & .62 & & & & & .39 & & & \\
\hline Phys1Freq & .53 & & & & & & .59 & & \\
\hline Phys2Freq & .63 & & & & & & .44 & & \\
\hline Emb1Freq & .59 & & & & & & & .55 & \\
\hline Emb2Freq & .64 & & & & & & & .44 & \\
\hline Care1Freq & .48 & & & & & & & & .61 \\
\hline Care2Freq & .64 & & & & & & & & .33 \\
\hline Con1Imp & & .45 & & .71 & & & & & \\
\hline Con2Imp & & .62 & & .46 & & & & & \\
\hline ChallImp & & .43 & & & .74 & & & & \\
\hline Chal2Imp & & .60 & & & .46 & & & & \\
\hline Give1Imp & & .44 & & & & .66 & & & \\
\hline Give2Imp & & .53 & & & & .53 & & & \\
\hline Phys1Imp & & .45 & & & & & .67 & & \\
\hline Phys2Imp & & .52 & & & & & .49 & & \\
\hline Emb1Imp & & .50 & & & & & & .68 & \\
\hline Emb2Imp & & .58 & & & & & & .55 & \\
\hline Care1Imp & & .44 & & & & & & & .70 \\
\hline Care2Imp & & .60 & & & & & & & .39 \\
\hline Con1Pres & & & .71 & -.33 & & & & & \\
\hline Con2Pres & & & .77 & -.21 & & & & & \\
\hline Chal1Pres & & & .71 & & -.33 & & & & \\
\hline Chal2Pres & & & .73 & & -.16 & & & & \\
\hline Give1Pres & & & .71 & & & -.29 & & & \\
\hline Give2Pres & & & .75 & & & -.26 & & & \\
\hline Phys1Pres & & & .71 & & & & -.27 & & \\
\hline Phys2Pres & & & .72 & & & & .18 & & \\
\hline Emb1Pres & & & .75 & & & & & -.25 & \\
\hline Emb2Pres & & & .77 & & & & & -.21 & \\
\hline Care1Pres & & & .70 & & & & & & -.30 \\
\hline Care2Pres & & & .75 & & & & & & -.15 \\
\hline
\end{tabular}

Note. Eng = behaviour engagement; Imp = activity importance; Pres = activity pressure; Con $=$ connecting with others; Chal $=$ challenging oneself; Give $=$ giving to others; Phys $=$ engaging in physical activity; Emb = embracing the moment; Care $=$ caring for oneself 


\section{Supplementary Material 3: \\ Word Frequency Tabulation}

To examine idiographic responses, a series of word frequency tables were constructed using the following R packages: tidytext (Silge \& Robinson, 2016), tm (Feinerer \& Hornik, 2017), and SnowballC (Bouchet-Valat, 2013). For each behaviour domain, all responses on both examples for each behaviour domain were converted into a text document that was then preprocessed to remove capital letters, punctuation, and numbers. Stop words, i.e. words such as 'a', 'the', 'or', were removed using the "smart" lexicon in the tidytext package (Silge \& Robinson, 2016). Words that did not provide meaningful information about valued action were also removed (presented on next page). The remaining words were then reduced to their stems, i.e. words representing different forms of the same word were reduced to their core. For instance, the words 'behave', 'behaviour', 'behaviours', and 'behaving' were reduced to 'behav'. These stems were then manually converted into a complete word (some stems were not proper words, e.g., 'behav' instead of 'behave'). If a participant repeated the same word within the same example, that instance of the word was counted only once towards the total frequency count of that word. Therefore, the final frequency score for each word represented the number of examples in which that word was reported. The top 20 words for each behaviour domain are presented in Tables S6-S8.

\section{References}

Bouchet-Valat, M. (2013). SnowballC: Snowball stemmers based on the Clibstemmer UTF-8 library. R package version 0.5.1. https://CRAN.R-project.org/package=SnowballC Feinerer, I., \& Hornik, K. (2017). tm: Text Mining Package. R package version 0.7-3. https://CRAN.R-project.org/package=tm

Silge, J., \& Robinson, D. (2016). tidytext: Text mining and analysis using tidy data principles in r. The Journal of Open Source Software, 1. doi: 10.21105/joss.00037 
The following words were deleted from the six domain factor word clouds:

"adequate", "adequately", "afternoon", "afternoons", "alot", "amount", "avoid", "back", "basic", "basically", "big", "bring", "busy", "cant", "common", "commonly", "daily", "day", “days", "dont", "easily", "end", "ending", "engage", "ensure", "even", "every", "everyday", "extend", "extensive", "extra", "extras", "favorite", "favorites", "favourite", "favourites", “feel", "feeling", "feels", "find", "finding", "finds", "frequent", "frequently", "friday", "full", "fully", "happen", "havent", "high", "hour", "hours", "ive", "keep", "keeping", "leave", "length", "list", "long", “longer", "loose", "lose", "lot", "lots", "low", "min", "minute", "minutes", "monday", "month", "months", "morning", "mornings", "next", "night", "nights", "nil", "nill", "open", "pay", "place", "plenty", "previous", "proper", "properly", "put", "puts", "regular", "regularly", "saturday", "set", "short", "shorter", "small", "space", "start", "starting", “stay", "stuff", "sunday", "take", "takes", "taking", "theyr", "thing", "things", "thursday", "time", "times", "timing" , "tuesday", "typical", "typically", "way", "ways", "wednesday", "week", "weeks", "what", "wont", "wouldnt", "wrong", "year". 
Table S3

Top 20 most frequent words reported by participants in Study 1.

\begin{tabular}{|c|c|c|c|c|c|c|}
\hline $\begin{array}{l}\text { Connecting } \\
\text { with Others }\end{array}$ & $\begin{array}{l}\text { Challenging } \\
\text { Oneself }\end{array}$ & $\begin{array}{l}\text { Giving to } \\
\text { Others }\end{array}$ & $\begin{array}{l}\text { Physical } \\
\text { Activity }\end{array}$ & $\begin{array}{l}\text { Embracing } \\
\text { the Moment }\end{array}$ & $\begin{array}{l}\text { Caring for } \\
\text { Oneself }\end{array}$ & Other \\
\hline friend & learn & donate & walk & enjoy & eat & care \\
\hline talk & cook & volunteer & play & watch & sleep & read \\
\hline phone & work & help & gym & attention & healthy & family \\
\hline facebook & read & friend & run & food & exercise & give \\
\hline converse & recipe & money & work & beautiful & diet & connect \\
\hline text & food & make & $\operatorname{dog}$ & notice & relax & love \\
\hline family & make & people & exercise & listen & walk & spend \\
\hline internet & skill & charity & jog & picture & food & help \\
\hline call & fix & work & bike & love & watch & play \\
\hline social & play & family & weight & nature & maintain & challenge \\
\hline interact & exercise & food & dance & people & drink & make \\
\hline people & goal & church & ride & play & shower & work \\
\hline email & online & clothes & swim & good & work & embrace \\
\hline media & book & kind & yoga & family & bath & people \\
\hline dinner & walk & listen & lift & walk & good & moment \\
\hline person & project & neighbour & friend & sit & read & good \\
\hline active & class & care & clean & curious & make & active \\
\hline visit & push & stranger & sport & life & rest & watch \\
\hline message & game & homeless & house & spend & water & friend \\
\hline online & home & cook & hike & sunset & vitamin & prayer \\
\hline
\end{tabular}


Table S4

Top 20 most frequent words reported by participants in Study 2.

\begin{tabular}{|c|c|c|c|c|c|c|}
\hline $\begin{array}{l}\text { Connecting } \\
\text { with Others }\end{array}$ & $\begin{array}{l}\text { Challenging } \\
\text { Oneself }\end{array}$ & $\begin{array}{l}\text { Giving to } \\
\text { Others }\end{array}$ & $\begin{array}{l}\text { Physical } \\
\text { Activity }\end{array}$ & $\begin{array}{l}\text { Embracing } \\
\text { the Moment }\end{array}$ & $\begin{array}{l}\text { Caring for } \\
\text { Oneself }\end{array}$ & Other \\
\hline friend & learn & donate & walk & enjoy & eat & care \\
\hline talk & cook & volunteer & gym & watch & healthy & play \\
\hline converse & work & help & play & food & sleep & friend \\
\hline social & skill & charity & run & attention & diet & read \\
\hline family & food & friend & exercise & notice & exercise & challenge \\
\hline facebook & study & people & work & curious & relax & connect \\
\hline phone & read & work & swim & listen & food & active \\
\hline internet & play & make & sport & beautiful & maintain & game \\
\hline media & exercise & money & $\operatorname{dog}$ & appreciate & good & work \\
\hline interact & fix & family & jog & people & shower & give \\
\hline people & develop & food & garden & family & drink & people \\
\hline online & goal & listen & bike & friend & make & love \\
\hline connect & push & advice & friend & play & work & spend \\
\hline chat & make & kind & dance & walk & walk & watch \\
\hline meet & recipe & offer & ride & love & watch & garden \\
\hline text & improve & cook & cycle & photo & health & listen \\
\hline call & response & support & home & nature & clean & physical \\
\hline dinner & online & children & soccer & good & read & travel \\
\hline work & gym & care & yoga & laugh & gym & video \\
\hline person & task & good & house & life & fit & life \\
\hline
\end{tabular}


Table S5

Top 20 most frequent words reported by participants from the adolescent sample in Study 3.

\begin{tabular}{|c|c|c|c|c|c|c|}
\hline $\begin{array}{l}\text { Connecting } \\
\text { with Others }\end{array}$ & $\begin{array}{l}\text { Challenging } \\
\text { Oneself }\end{array}$ & $\begin{array}{l}\text { Giving to } \\
\text { Others }\end{array}$ & $\begin{array}{l}\text { Physical } \\
\text { Activity }\end{array}$ & $\begin{array}{l}\text { Embracing } \\
\text { the Moment }\end{array}$ & $\begin{array}{l}\text { Caring for } \\
\text { Oneself }\end{array}$ & Other \\
\hline friend & learn & help & play & enjoy & sleep & care \\
\hline converse & skill & friend & sport & appreciate & healthy & active \\
\hline talk & work & kind & walk & attention & eat & friend \\
\hline people & develop & people & netball & notice & relax & challenge \\
\hline active & response & volunteer & run & beautiful & diet & family \\
\hline social & school & donate & dance & food & make & connect \\
\hline interact & sport & make & friend & people & exercise & make \\
\hline school & cook & charity & school & curious & maintain & work \\
\hline media & goal & school & $\operatorname{dog}$ & friend & care & physical \\
\hline internet & hard & work & gym & world & hard & happy \\
\hline family & study & money & tennis & person & good & kind \\
\hline sport & push & stranger & touch & photo & food & enjoy \\
\hline weekend & instrument & family & row & life & school & moment \\
\hline make & play & support & swim & surround & sport & sport \\
\hline text & active & offer & hockey & family & bed & help \\
\hline meet & music & house & weekend & live & active & school \\
\hline online & comfort & happy & jog & make & work & person \\
\hline play & zone & listen & train & listen & balance & hard \\
\hline catch & people & community & soccer & phone & break & embrace \\
\hline spend & make & homework & team & unusual & watch & positive \\
\hline
\end{tabular}

